\title{
¿REHABILITAR PATRIMONIO O ESCOLARIZAR A LA POBLACIÓN? GASTO PÚBLICO EN LA SEVILLA DE MEDIADOS DEL SIGLO XIX
}

\author{
Rehabilitate heritage or schooling the population? Public expenditure in the \\ middle century of Sevilla
}

\author{
Antonio J. Daza Sierra \\ Universidad Pablo de Olavide \\ adazie@upo.es \\ Orcid: 0000-0002-0614-0130
}

Recibido: 19-04-2020 - Aceptado: 21-07-2020

\author{
Cómo citar este artículo/Citation: \\ Antonio J. Daza Sierra, “Rehabilitar patrimonio o \\ escolarizar a la población? Gasto público en la Sevilla de \\ mediados del siglo XIX”, Hispania Nova, 19 (2021): 72 a \\ 105 . \\ DOI: https://doi.org/10.20318/hn.2021.5876
}

\begin{abstract}
Copyright: (c) HISPANIA NOVA es una revista debidamente registrada, con ISSN 1138-7319 y Depósito Legal M 9472-1998. Los textos publicados están -si no se indica lo contrario- bajo una licencia Reconocimiento-Sin obras derivadas 3.0 España de Creative Commons. Puede copiarlos, distribuirlos y comunicarlos públicamente siempre que cite su autor y la revista y la institución que los publica y no haga con ellos obras derivadas. La licencia completa se puede consultar en: http://creativecommons.org/licenses/by-nd/3.0/es/deed.es
\end{abstract}

Resumen: Este artículo reflexiona sobre la provisión de servicios educativos públicos en la ciudad de Sevilla durante la Década Moderada, poniendo de manifiesto la contradicción entre la legislación nacional y la práctica local en la creación y puesta en funcionamiento de las escuelas públicas. El análisis de la documentación municipal demuestra cómo las obligaciones de los Ayuntamientos crecieron acompañadas de restricciones presupuestarias. Las decisiones de las autoridades locales, en última instancia, beneficiaron los intereses de las élites urbanas, y los escasos fondos destinados a la educación primaria se desviaron hacia la rehabilitación de edificios y el establecimiento de centros de enseñanza secundaria, en perjuicio de las necesidades de las clases populares y contraviniendo las normativas nacionales.
Palabras clave: Escuelas, presupuestos, actas, élites, desigualdad social.

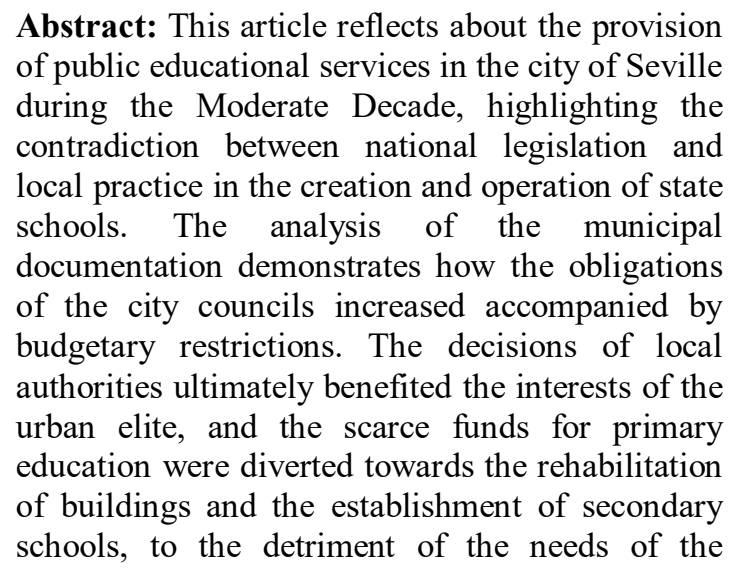
schools, to the detriment of the needs of the 
working class and contravening national Keywords: Schools, budgets, minutes, elite, regulations. social inequality.

\section{INTRODUCCIÓN}

La transición del Antiguo Régimen al Estado Liberal supuso cambios legislativos, pero las prácticas se mantuvieron, se crearon las condiciones para que naciera el caciquismo. Como ha señalado Comín, la Hacienda Pública renunció a una administración tributaria con los medios técnicos y humanos capaces de hacer cumplir la legislación, y la sociedad española acabó pagando el precio de una Administración ineficiente ${ }^{1}$.

El presente artículo analiza los fondos públicos que se recaudaban con el objetivo de financiar la educación, estos fondos se terminaron destinando en Sevilla a otros fines, como por ejemplo la rehabilitación de edificios. A partir de la documentación generada por la Comisión Local de Instrucción Primaria, los presupuestos municipales, y la correspondencia entre los miembros de la corporación municipal de Sevilla, se muestra cómo se incumplía sistemáticamente la legislación nacional relativa a la creación de escuelas entre los años 1844 y 1854 . La Ley de Instrucción Primaria de 21 de julio de 1838, y su posterior desarrollo reglamentario con Montesinos tuvieron un gran impacto en las localidades más densamente pobladas, y fue muy débil en el resto ${ }^{2}$. El siguiente hito fue el Plan Pidal de 1845, donde se reafirma que la educación es una materia de interés público cuyo control pertenece al Estado; si bien se renuncia a una educación universal y gratuita en todos los grados.

El Real Decreto de 23 de septiembre de 1847 en su Título IV, artículo 32 exigía que en las poblaciones de crecido vecindario había de existir siempre una Escuela elemental completa de niños y otra de niñas por cada 500 vecinos entre públicas y privadas; la tercera parte por lo menos deberá ser de la primera especie, es decir

\footnotetext{
${ }^{1}$ F. Comín "La corrupción permanente: el fraude fiscal en España”. Revista de Historia Contemporánea Hispania Nova, 2018, número 16, pp. 481-521.

${ }^{2}$ R. Ojeda "Aproximación al estado de la educación a mediados del siglo XIX a través del diccionario de Madoz: El caso de La Rioja”. Berceo, Logroño, 1999, N 136, pp. 145.
} 
públicas $^{3}$. Al promulgarse la Ley Moyano en 1857 Sevilla capital sólo contaba con seis escuelas públicas de niños y ocho de niñas, cuando para escolarizar a la población infantil existente la propia ley ordenaba la creación de más del doble. En el año 1857 Sevilla capital tenía 112.529 habitantes, y le eran necesarias trece escuelas más de niños y once de niñas, sumando diecinueve por cada sexo. La Junta Provincial lo había comunicado oportunamente al Ayuntamiento, tenía que haber 38 escuelas públicas y había 14, por lo tanto, faltaban 24 escuelas públicas ${ }^{4}$.

Las clases altas educaban a sus hijos en sus propias casas durante la Instrucción Primaria, mientras potenciaban la Segunda Enseñanza de difícil acceso para los sectores populares $^{5}$. Esta tendencia nace a finales del siglo XVIII, y fue en incremento entre las clases pudientes $^{6}$. La enseñanza primaria solamente sería gratuita para los niños pobres (Real Decreto de 4 de agosto de 1836).

Respecto a los presupuestos la reforma Mon-Santillán de 1845 fue sesgada, debido a los grupos de presión representados en las Cortes, que consiguieron evitar que se les incrementase la presión fiscal de dos maneras: consiguiendo parar la iniciativa que propugnaba la creación de un catastro que identificara de forma correcta las bases imponibles de los contribuyentes, y dejando en manos de las corporaciones municipales el reparto y asignación de los tributos. La negativa de las elites locales a asumir más obligaciones tributarias configuró unas altas tasas de analfabetismo.

Acemoglu y Robinson denominan élites extractivas a las minorías que se apropian de las instituciones para concentrar el poder económico y político ${ }^{7}$.

La investigación realizada por Espigado nos pone de manifiesto las similitudes y diferencias existentes entre Cádiz y Sevilla, ciudades con luz propia en los siglos

\footnotetext{
${ }^{3}$ AHMS Sesión de 17 de enero de 1848: "La Comisión local de instrucción primaria del ayuntamiento de Sevilla expresa con rotundidad que el citado ayuntamiento se halla en la imposibilidad de cumplir con lo dispuesto en el Real Decreto".

${ }^{4}$ A. Montero (1996): "La enseñanza primaria pública en Sevilla (1857-1900). Desde la promulgación de la Ley Moyano hasta la creación del Ministerio de Instrucción Pública”. (Sevilla: Universidad de Sevilla, 1996), pp. 68. AHMS. Ngd ${ }^{\circ}$ I. P. Legajo 7. 21-junio-1858."Documento de la Junta Provincial dirigido al Ayuntamiento".

5 AHMS Actas de la Comisión Local de Instrucción Primaria Sesión de 10 de enero de 1845. Edificio en calle Maese Rodrigo planificado para Instrucción Primaria y finalmente destinado a Enseñanza Secundaria.

${ }^{6}$ F. Aguilar "La enseñanza primaria en Sevilla durante el siglo XVIII". Boletín de la Real Academia Sevillana de Buenas Letras, 1973, vol. 1, pp. 39-83.

${ }^{7}$ D. Acemoglu y J. Robinson, ¿Por qué fracasan los países? Los orígenes del poder, la prosperidad y la pobreza. (Editorial Deusto, Barcelona, 2012).
} 
precedentes, que ven disminuido su capital humano de forma drástica comparativa con el resto de España ${ }^{8}$.

El texto se estructura de la siguiente manera: tras esta introducción, el segundo apartado está dedicado a explicar las fuentes en las que se apoya la investigación. E1 siguiente apartado justifica la importancia del capital humano en base a una breve revisión de la literatura, y demuestra, con datos de 1855 obtenidos del Instituto Nacional de Estadística (INE), la diferencia en la implantación de escuelas públicas en España comparando el Norte y el Sur; el cuarto apartado aborda, desde la visión y análisis de las actas y los presupuestos, una primera etapa cronológica, los años comprendidos entre 1844 y 1850, en los que se aprecian los efectos de la Reforma Mon/Santillán sobre la financiación de la Instrucción Primaria en el ámbito local; el quinto apartado recoge el periodo 1851-1854, marcado por las injerencias del Jefe Político y la Comisión Superior en la construcción y puesta en funcionamiento de las escuelas públicas. El sexto cierra el artículo con unas breves conclusiones.

\section{INSTRUCCIÓN PÚBLICA E INSTITUCIONES LOCALES: FUENTES}

La investigación ha utilizado tres tipos de fuentes del Archivo Histórico Municipal de Sevilla (AHMS): la información generada por la Comisión Local de Instrucción Primaria, los presupuestos municipales y la correspondencia entre los miembros de la corporación municipal. Laspalas indica, en su estudio sobre las escuelas primarias en España, que la documentación más importante y accesible está en los archivos municipales ${ }^{9}$.

La Hacienda local sevillana del siglo XIX apenas ha sido estudiada desde la caída del Antiguo Régimen hasta la primera mitad del siglo. Un conocimiento de los barrios de la ciudad y la ubicación de los conventos desamortizados ha permitido

\footnotetext{
${ }^{8}$ G. Espigado, Aprender a leer y escribir en el Cádiz del 800. (Universidad de Cádiz, Cádiz, 1996).

9 J. Laspalas. "Primary Schools in Eighteenth-Century Spain: Assessment and Research Perspectives". History of Education \& Children's Literature. Vol.7 nº 2, 2012. pp. 11-32.
} 
configurar un mapa de la realidad educativa primaria municipal en el periodo analizado. Esta investigación utiliza técnicas próximas a la microhistoria ${ }^{10}$.

En la historiografía especializada, Aguilar ha utilizado estas fuentes para valorar el papel de la instrucción pública entre mediados del siglo XVIII y principios del siglo $\mathrm{XIX}^{11}$. Collado ha analizado el papel de las Sociedades Económicas de Amigos del País $^{12}$. Montero ha valorado el impacto producido por la implementación en la segunda mitad del siglo XIX de la Ley Moyano ${ }^{13}$, y Almuedo ha descrito su capacidad industrial $^{14}$. Hay periodos donde las actas no se conservan, pero sí los presupuestos. A medida que avanza la década de los cuarenta, se va uniformando la forma de presentar las cuentas como consecuencia de la organización fiscal de Mon-Santillán.

Los presupuestos son más sistemáticos desde 1845, aunque el propio Ayuntamiento, a través de sus representantes, manifiesta en ocasiones desconocer la normativa vigente, discutiendo en ocasiones su idoneidad. Entre los documentos anexos a los presupuestos, o a las actas de la Comisión Local de Instrucción Primaria hay relevantes detalles de la correspondencia entre miembros del ayuntamiento, a su vez miembros de la Comisión Local de Instrucción Primaria, y el Jefe Político. Las actas de la Comisión Local conformaban los presupuestos relativos a la creación de escuelas, que luego eran elevados al ayuntamiento para su aprobación e inclusión en los presupuestos de la hacienda municipal, en última instancia eran supervisados por el Jefe Político que dependía del gobierno central. Los debates, sugerencias, y las decisiones tomadas en la Comisión Local permiten conocer los criterios empleados respecto a la creación de escuelas municipales de instrucción primaria. Las revisiones de los presupuestos por el ayuntamiento y el Jefe Político permiten observar las tensiones existentes. Estas

\footnotetext{
${ }^{10}$ G. Levi., La herencia inmaterial: La historia de un exorcista piamontés del siglo XVII,. (Edición Nerea, Madrid, 1990). Análisis microhistórico "se basa esencialmente en la reducción de la escala de observación, en un análisis microscópico y en un estudio intensivo del material documental".

11 F. Aguilar "La enseñanza primaria en Sevilla durante el siglo XVIII". Boletín de la Real Academia Sevillana de Buenas Letras, 1973, vol. 1, pp. 39-83.

${ }^{12}$ M. Collado "Proyecto de la Real Sociedad Económica del Amigos del País, de establecimientos de escuelas gratuitas para la ciudad de Sevilla, en el año 1837”. Cuestiones Pedagógicas 2, 1985, pp. 143150.

${ }^{13}$ A. Montero, La enseñanza primaria pública en Sevilla (1857-1900). Desde la promulgación de la Ley Moyano hasta la creación del Ministerio de Instrucción Pública. (Sevilla: Universidad de Sevilla, 1996).

${ }^{14}$ J. Almuedo “Ciudad e industria: Sevilla, 1850-1930”. Diputación Provincial de Sevilla, 1996.
} 
escuelas tenían un carácter gratuito para los que acreditaban ser "pobres de solemnidad".

Las secciones consultadas, indicando la colección alfabética con los años correspondientes, han sido las siguientes: AHMS Presupuestos Sección XX C.A. 11791241 años 1833-1857. AHMS Actas Comisión Local de Instrucción Primaria Sección XX 1840-1859 C.A.79-80, 1093.

\section{IMPORTANCIA DE LA IMPLANTACIÓN DE LAS ESCUELAS PÚBLICAS Y SITUACIÓN EN ESPAÑA TRAS LA DÉCADA MODERADA}

Existe una amplia literatura, con un detallado apoyo empírico, que muestra la relación existente entre la desigualdad y el capital humano. Laspalas incide en la estructura socioeconómica como uno de los factores que favorecía la demanda de escuelas. La estructura de la propiedad de la tierra en el sur de España con el sistema de latifundios no incentivó a enviar a las escuelas a los hijos de los trabajadores agrícolas. Sin embargo, en el norte con la propiedad de la tierra más dividida sí existió un mayor interés por la escolarización. Igualmente, señala a la composición del gobierno municipal, donde en el sur estaba controlado por una élite propietaria de la mayoría de las tierras. Como consecuencia las escuelas en el sur estaban más masificadas al existir en menor número por habitantes ${ }^{15}$.

La investigación en los Estados Unidos durante la segunda mitad del siglo XIX, y principios del siglo $\mathrm{XX}$, evidencia que la desigualdad tuvo un efecto adverso sobre el desarrollo económico, tal y como indica Galor ${ }^{16}$. Go y Lindert muestran como factores que determinaron el desarrollo de las escuelas en el Norte de los Estados Unidos frente a los estados del Sur en 1850 los bajos precios en relación a las rentas obtenidas en el

\footnotetext{
${ }^{15}$ J. Laspalas. "Primary Schools in Eighteenth-Century Spain: Assessment and Research Perspectives". History of Education \& Children's Literature. Vol.7 n 2, 2012. pp. 11-32

16 O. Galor. "Inequality and Economic Development". An overview. Working papers from Brown University 3, 2009.
} 
Norte, el diferente grado de autonomía del gobierno local en la toma de decisiones, y la conciencia de la importancia del voto entre la ciudadanía entre las personas del Norte ${ }^{17}$.

Beltrán et al. plantean la relación existente entre desigualdad y formación de capital humano, usando información extraída de los padrones municipales. Las crecientes investigaciones evidencian que la desigualdad en el acceso a la propiedad de la tierra tuvo un impacto negativo en los resultados educativos, lo que implicó que las instituciones afectaran a la acumulación de capital humano ${ }^{18}$.

En una línea paralela, Galor, Moav y Vollrath, demuestran la forma en la cual el conflicto deriva a otro adicional entre la élite arraigada terrateniente y la élite capitalista emergente que compite por el poder y el estatus ${ }^{19}$.

Indica Juif que privar de educación a una parte de la población puede significar un reparto poco eficiente de los recursos. Privar a las mujeres de la educación puede tener consecuencias negativas para el bienestar, las mujeres mejor educadas tienden a mejorar los niveles de nutrición y prevenir enfermedades en sus familias, reduciendo la mortalidad $^{20}$.

Mokyr sostiene que los avances tecnológicos estaban determinados, no tanto por las reservas de capital humano, como por su distribución, y la tendencia del sistema educativo a enseñar no sólo habilidades técnicas, sino también la capacidad de acceder y absorber conocimiento y luego utilizarlo de forma creativa ${ }^{21}$.

Bajo el análisis de estas premisas hemos estudiado el caso de la ciudad de Sevilla. Centramos el debate en las inversiones llevadas a cabo en escuelas a través de la configuración de los presupuestos, el poder municipal, y la influencia en la oferta educativa primaria gratuita a través de las políticas de asignación del gasto. Analizamos

\footnotetext{
${ }^{17}$ S. Go y P. Lindert "The Uneven Rise of American Public Schools to 1850". The Journal of Economic History 70 (1), pp. 1-26, 2010.

${ }^{18}$ F. Beltrán, A. Díez-Minguela, y J. Martínez-Galarraga, "The shadows of cities: Size, location and the spatial distribution of population in Spain". Cambridge Working Paper Economics: 1749. (University of Cambridge, 2017). F. Beltrán, A. Díez-Minguela, y J. Martínez-galarraga. "Tracing the Evolution of Agglomeration Economies: Spain, 1860-1991”. The Journal of Economic History 78 (1), 2018, pp. 81117.

${ }^{19}$ O. Galor, O. Moav y D. Vollrath "Inequality in Landownership, the Emergence of Human-Capital Promoting Institutions, and the Great Divergence." Review of Economic Studies. Oxford University Press 76 (1), pp. 143-179, 2009.

${ }^{20}$ D. Juif, Determinants of Long-Run Human Capital Formation. (PHD in Economic History. Tubinga: Universidad de Tubinga, 2014).

${ }^{21}$ J. Mokyr, The Enlightened Economy: An Economic History of Britain 1700-1850. (New Haven, Yale University Press, 2010).
} 
la oferta educativa, siendo el stock educativo, en la línea seguida por Núñez, la clave entre los dos componentes más importantes del capital humano: la salud, y el conocimiento $^{22}$.

La extensión del sufragio promovió la escolarización masiva, pero la financiación de la escolarización continuó en manos de los consejos locales, dificultades financieras y sus actitudes hacia la educación, contribuyeron a niveles insuficientes de gastos de escolaridad ${ }^{23}$.

En los cuadros 1 y 2 se han recogido los datos de las provincias con mayor/menor número de escuelas por habitante en 1855. El cuadro 1, a su vez, indica la composición del alumnado por sexos y el total de alumnos estableciendo un porcentaje de número de escuelas por habitante ordenado de forma descendente. El cuadro 2 nos distingue entre públicas, privadas y religiosas. Se aprecia que el mayor porcentaje de escuelas por habitantes se encontraba en el norte de España (fundamentalmente, la actual Castilla-León). Por el contrario, las provincias con un menor porcentaje de escuelas por habitante se ubicaban en Andalucía, las islas Canarias y Baleares, incluyendo las provincias catalanas de Barcelona y Gerona. Mientras en Soria, Burgos o León había una ratio de 0,39, 0,38 y 0,30 escuelas por habitante, en Sevilla, Badajoz y Granada esta ratio desciende a 0,09, 0,09 y 0,08 respectivamente. Este dato se obtiene dividiendo el número de escuelas entre el total de habitantes según datos del censo de 1855 obtenidos del Instituto Nacional de Estadística (INE). Respecto a la región andaluza, la mayoría de sus provincias -ordenadas de menor a mayor, Almería, Cádiz, Málaga, Jaén, Córdoba, Granada y Sevilla- tenían porcentajes de escuelas por habitante inferiores al $0,10 \%$.

La financiación de la instrucción primaria dependía de los ayuntamientos, luego se deduce que las diferentes políticas municipales tuvieron como consecuencia diferentes resultados. Como prueba de ello, se observa que las provincias con mayor número de escuelas por habitantes destacan por el número de escuelas públicas. Las anteriormente citadas Soria, Burgos o León tenían 562, 1179 y 1039 escuelas públicas mientras Sevilla tenía 230 y Badajoz y Granada 263 y 286 respectivamente. La

\footnotetext{
${ }^{22}$ C. Núñez. "Los determinantes del atraso educativo" en A. Carreras y X. Tafunell (eds) Estadísticas Históricas de España siglos XIX-XX. (Bilbao: Fundación BBVA, 2005).

${ }^{23}$ C. Núñez, La fuente de la riqueza. Educación y desarrollo económico en la España Contemporánea. (Madrid, Alianza Editorial, 1992).
} 
inversión en escuelas públicas que hacen los municipios es la que provocaba las diferentes tasas de alfabetización motivada por la diferente oferta de escolarización. Mientras es elevado el número de escuelas públicas en las provincias de Castilla-León, hay poblaciones con más escuelas particulares que públicas en Andalucía, siendo los casos de Huelva o Cádiz. Las escuelas particulares en Cádiz ascendían a 141 frente a 128 escuelas públicas y en Huelva ascendían las escuelas particulares a 123 frente a 109 escuelas públicas. La dejación de asumir sus competencias por los municipios de Huelva o Cádiz, y la oferta educativa mayor de escuelas particulares denota la menor implicación pública en defensa de la instrucción de toda su población. Gloria Espigado indica que la lucha de los liberales por la implantación de escuelas públicas desde la Constitución de 1812 perseguía eliminar el monopolio de la Iglesia en la docencia. La ciudad de Cádiz al igual que Sevilla contaba con una oferta educativa que convirtió en un desafío el desarrollo de la instrucción pública en dicha ciudad en la transición del Antiguo Régimen.

En Cádiz existió un pulso entre la escuela pública y la privada, y al igual que ocurrió en Sevilla fue un inconveniente la concentración de escuelas en edificios desamortizados, distribuidos de forma muy irregular en la ciudad. Cózar y García hacen mención al factor económico como determinante en los municipios para la financiación de las escuelas vinculándolos a los bienes de propios, informando de escuelas de primeras letras en conventos a finales del Antiguo Régimen. Esta financiación se complementaba con ayudas de los padres y la existencia de obras pías y fundaciones. Nos mencionan casos como Lezuza donde con 310 vecinos mantenían dos escuelas de primeras letras costeadas por el ayuntamiento entre los años 1782 y 1787 aduciendo los motivos a una hacienda saneada o el carácter ilustrado de los regidores municipales ${ }^{24}$. Gómez indica que en lugares como La Rioja los maestros de primeras letras gozaban de una situación muy favorable siendo aceptada su condición de servicio público y pagados por los concejos municipales y los padres ${ }^{25}$. Martínez nos muestra como los procesos desamortizadores terminaron por colapsar la estructura asistencial de la Iglesia, el Estado liberal inicia una etapa de transición que llevaría desde la caridad a la

\footnotetext{
${ }^{24}$ R. Cózar y F. García. "La Enseñanza De Primeras Letras En Las Tierras De Albacete a Finales Del Antiguo Régimen". Tiempos modernos: Revista Electrónica de Historia Moderna, volumen 8, $\mathrm{n}^{\circ}$ 31, 2015, pp 68-72.

${ }^{25}$ J.L. Gómez et al. "Los maestros de primeras letras en La Rioja a mediados del siglo XVIII". Cuadernos de investigación histórica, Universidad de La Rioja, 2019, pp. 127.
} 
Antonio J. Daza Sierra

¿Rehabilitar patrimonio o escolarizar a la población? Gasto público en la Sevilla de mediados del siglo XIX

beneficencia pública, pero el liberalismo español ante las insuficiencias presupuestarias fue incapaz de articular un sistema público asistencial en la primera mitad del siglo $\mathrm{XIX}^{26}$. Como indica Collantes, los niveles de alfabetización estuvieron ligados a la oferta educativa $^{27}$. Barquín identifica como variables la influencia de la Iglesia, la capitalidad provincial, la presencia del ferrocarril, la actividad industrial y minera, y los programas de alfabetización de los regímenes liberales ${ }^{28}$.

Cuadro 1. Provincias con mayor número de escuelas por habitante, 1855

\begin{tabular}{|c|c|c|c|c|c|c|}
\hline Provincia & $\begin{array}{c}\mathrm{N}^{0} \\
\text { habitantes }\end{array}$ & $\begin{array}{c}\mathbf{N}^{\mathbf{o}} \\
\text { Escuelas }\end{array}$ & $\mathbf{N}^{0}$ Alumnos & $\begin{array}{c}\mathbf{N}^{\mathbf{o}} \\
\text { Alumnas }\end{array}$ & $\begin{array}{c}\text { Total } \\
\text { alumnos/as }\end{array}$ & $\begin{array}{l}N^{0} \text { escuelas por } \\
\text { habitante }\end{array}$ \\
\hline Soria & 147.468 & 573 & 11.307 & 5.695 & 17.002 & 0,39 \\
\hline Burgos & 333.356 & 1.253 & 22.836 & 14.003 & 36.839 & 0,38 \\
\hline León & 348.756 & 1.063 & 30.151 & 1.291 & 31.442 & 0,30 \\
\hline Álava & 96.398 & 273 & 5.877 & 3.975 & 9.852 & 0,28 \\
\hline Guadalajara & 199.088 & 500 & 15.184 & 2.792 & 17.976 & 0,25 \\
\hline Lugo & 424.186 & 1.013 & 24.785 & 4.855 & 29.640 & 0,24 \\
\hline Segovia & 146.389 & 328 & 9.480 & 5.099 & 14.579 & 0,22 \\
\hline Palencia & 185.970 & 386 & 13.208 & 3.776 & 16.984 & 0,21 \\
\hline Teruel & 238.628 & 494 & 12.399 & 9.558 & 21.957 & 0,21 \\
\hline Santander & 214.441 & 424 & 15.222 & 6.073 & 21.295 & 0,20 \\
\hline Navarra & 297.422 & 582 & 19.776 & 14.040 & 33.816 & 0,20 \\
\hline Salamanca & 263.516 & 508 & 20.093 & 2.057 & 22.150 & 0,19 \\
\hline Ávila & 164.039 & 292 & 9.447 & 1.306 & 10.573 & 0,18 \\
\hline Logroño & 173.812 & 309 & 12.073 & 6.078 & 18.151 & 0,18 \\
\hline Zamora & 249.162 & 438 & 13.215 & 4.387 & 17.062 & 0,18 \\
\hline Cuenca & 229.959 & 403 & 10.714 & 5.932 & 16.646 & 0,18 \\
\hline Valladolid & 244.023 & 412 & 14.849 & 8.015 & 22.864 & 0,17 \\
\hline Huesca & 257.839 & 409 & 11.420 & 3.689 & 15.109 & 0,16 \\
\hline Oviedo & 524.529 & 830 & 33.042 & 9.704 & 42.746 & 0,16 \\
\hline Toledo & 328.755 & 451 & 13.723 & 8.263 & 21.896 & 0,14 \\
\hline Zaragoza & 384.176 & 518 & 15.845 & 7.537 & 23.382 & 0,13 \\
\hline Valencia & 606.608 & 816 & 23.845 & 23.582 & 47.067 & 0,13 \\
\hline Huelva & 174.391 & 234 & 6.984 & 5.200 & 12.184 & 0,13 \\
\hline
\end{tabular}

${ }^{26}$ A.P. Martínez "La protección social en la época liberal: de la beneficencia a la previsión social (18201908)". Revista Internacional de Ciencias Sociales, [s. 1.], n. 37, 2018, pp. 110-112.

${ }^{27}$ F. Collantes. "Las disparidades educativas en la España rural contemporánea, 1860-2000: un análisis comparado de las comarcas montañosas", Revista de Demografía Histórica. Volumen XXII, II, 2004, segunda época, pp.15-52

${ }^{28}$ F. Barquín, P. Pérez, y B. Sanz. "Literacy in Spain in the 19TH century: an econometric análisis", Asociación Española de Historia Económica. DT-AEHE Nº 1615, 2016. ISSN 2174-4912. 
ANTONiO J. DAZA SIERRA

¿Rehabilitar patrimonio o escolarizar a la población? Gasto público en la Sevilla de mediados del siglo XIX

\begin{tabular}{|c|c|c|c|c|c|c|}
\hline Provincia & $\begin{array}{c}\mathbf{N}^{\circ} \\
\text { habitantes }\end{array}$ & $\begin{array}{c}\mathbf{N}^{\mathbf{o}} \\
\text { Escuelas }\end{array}$ & $\mathrm{N}^{\circ}$ Alumnos & $\begin{array}{c}\mathbf{N}^{\mathbf{o}} \\
\text { Alumnas }\end{array}$ & $\begin{array}{c}\text { Total } \\
\text { alumnos/as }\end{array}$ & $\begin{array}{l}\mathbf{N}^{0} \text { escuelas por } \\
\text { habitante }\end{array}$ \\
\hline Tarragona & 320.593 & 417 & 13.122 & 6.211 & 19.333 & 0,13 \\
\hline Ciudad Real & 244.328 & 305 & 16.451 & 8.277 & 24.728 & 0,12 \\
\hline Vizcaya & 160.579 & 199 & 8.370 & 4.274 & 12.644 & 0,12 \\
\hline Castellón & 260.919 & 320 & 8.693 & 8.695 & 17.388 & 0,12 \\
\hline Cáceres & 302.134 & 363 & 13.614 & 5.966 & 19.580 & 0,12 \\
\hline Madrid & 475.785 & 546 & 16.811 & 11.498 & 28.309 & 0,11 \\
\hline Orense & 371.818 & 423 & 18.826 & 3.583 & 22.409 & 0,11 \\
\hline Guipúzcoa & 156.493 & 163 & 6.050 & 2.460 & 8.510 & 0,10 \\
\hline Lérida & 306.994 & 318 & 10.652 & 3.366 & 14.018 & 0,10 \\
\hline Coruña & 551.989 & 556 & 19.213 & 3.149 & 22.362 & 0,10 \\
\hline Albacete & 201.118 & 201 & 6.256 & 4.255 & 10.511 & 0,10 \\
\hline Alicante & 378.958 & 350 & 11.747 & 11.423 & 23.170 & 0,09 \\
\hline Sevilla & 463.486 & 415 & 14.767 & 11.679 & 26.446 & 0,09 \\
\hline Badajoz & 404.981 & 359 & 17.043 & 9.710 & 26.753 & 0,09 \\
\hline Granada & 444.629 & 376 & 12.745 & 5.989 & 18.734 & 0,08 \\
\hline Barcelona & 713.734 & 587 & 28.048 & 11.028 & 39.076 & 0,08 \\
\hline Córdoba & 351.536 & 288 & 11.620 & 8.726 & 20.346 & 0,08 \\
\hline Gerona & 310.970 & 238 & 11.002 & 2.944 & 13.946 & 0,08 \\
\hline Jaén & 345.879 & 259 & 11.135 & 7.771 & 18.906 & 0,07 \\
\hline Baleares & 262.893 & 194 & 5.122 & 4.670 & 9.792 & 0,07 \\
\hline Málaga & 451.406 & 323 & 18.077 & 11.211 & 29.288 & 0,07 \\
\hline Cádiz & 390.192 & 272 & 10.846 & 7.417 & 18.263 & 0,07 \\
\hline Almería & 315.664 & 198 & 6.666 & 2.551 & 9.217 & 0,06 \\
\hline Canarias & 234.046 & 137 & 3.411 & 1.584 & 4.995 & 0,06 \\
\hline Pontevedra & 428.886 & 231 & 11.590 & 943 & 12.533 & 0,05 \\
\hline Murcia & 380.969 & 197 & 7.665 & 4.030 & 11.695 & 0,05 \\
\hline
\end{tabular}

Fuente: elaboración propia a partir de datos INE 1855.

Indica Núñez, que existieron dos períodos de expansión de la alfabetización en España entre 1860 y 1930. El primer período expansivo, 1860-1900, es producto de la labor realizada por los municipios en los años 1833-1857. Este primer período afecta a la Submeseta Norte y regiones adyacentes, y en menor medida a Galicia. Se produce un distanciamiento frente al Sur de España, incluyendo Baleares y Canarias. El segundo período, que comprende entre los años 1900 y 1930, consigue la alfabetización universal del Norte ${ }^{29}$.

Como se puede observar en el cuadro 2 en aquellas provincias donde existía un mayor número de escuelas por habitantes el peso de la oferta educativa lo llevaba la

${ }^{29}$ C. Núñez y G. Tortella, La maldición divina. Ignorancia y atraso económico en perspectiva histórica. (Madrid, Alianza Editorial, 1993). 
escuela pública financiada por el ayuntamiento. En cambio, en las localidades andaluzas donde el porcentaje de escuelas por habitante eran los de menor oferta educativa en España, destacan las ofertas de escuelas particulares, lo que refleja una menor implicación del gasto público municipal y una necesidad que se satisface por las familias que se lo podían permitir con gasto privado.

El ayuntamiento sevillano hubiera podido invertir más fondos en instrucción primaria en función de dos variables (ingresos y gastos): desde el punto de vista de los ingresos obteniendo más fondos. No se podían crear más arbitrios, pero sí establecer recargos tanto en las contribuciones como en los arbitrios. Sin embargo, los que tomaban las decisiones no aumentaron ni la contribución de inmuebles, ni la contribución industrial, en la cantidad necesaria. Los grupos de presión en las Cortes impidieron la realización de un catastro que identificara adecuadamente las bases imponibles con una declaración real de la propiedad titular de cada contribuyente y sus ingresos reales.

La otra variable hubieran sido los gastos, pero los destinos prioritarios no fueron las actuaciones destinadas el fomento de la instrucción primaria, fueron más importantes las rehabilitaciones de los edificios conventuales desamortizados, protegiendo el legado del patrimonio existente, y se otorgó preferencia a suplir las carencias urbanísticas de la ciudad, ante el crecimiento de la población con el éxodo de población rural al área metropolitana. Existía la necesidad de acometer reformas ligadas a la higiene y la salubridad. Es elocuente el comentario del cronista de la historia de El Coronil: "Es verdad que la mayoría se encuentra en la necesidad de abandonar las contiendas o perecer de hambre, porque las llaves que abren las puertas del trabajo están unidas a la vara de la autoridad, transmitiéndose ésta de uno a otro como rica herencia legada por el más repugnante caciquismo" 30 .

\section{Cuadro 2. Número de escuelas públicas, privadas y religiosas}

\begin{tabular}{|l|c|c|c|c|c|c|}
\hline Provincia & $\mathbf{N}^{\mathbf{0}}$ habitantes & $\begin{array}{c}\mathbf{N}^{\mathbf{0}} \text { escuelas } \\
\text { públicas }\end{array}$ & $\begin{array}{c}\mathbf{N}^{\mathbf{0}} \text { escuelas } \\
\text { particulares }\end{array}$ & $\begin{array}{c}\mathbf{N}^{\mathbf{0}} \text { escuelas } \\
\text { entidades } \\
\text { religiosas }\end{array}$ & $\begin{array}{c}\text { Total } \\
\text { escuelas }\end{array}$ & $\begin{array}{c}\text { \% escuelas } \\
\text { públicas por } \\
\text { habitante }\end{array}$ \\
\hline Soria & 147.468 & 562 & 11 & & 573 & 0,38 \\
\hline
\end{tabular}

\footnotetext{
${ }^{30}$ A. Bernal, La lucha por la tierra en la crisis del Antiguo Régimen). (Madrid: Ed. Taurus. pp. 455, 1979).
} 
Antonio J. DAZA Sierra

¿Rehabilitar patrimonio o escolarizar a la población? Gasto público en la Sevilla de mediados del siglo XIX

\begin{tabular}{|c|c|c|c|c|c|c|}
\hline Provincia & $\mathbf{N}^{0}$ habitantes & $\begin{array}{l}\text { Noescuelas } \\
\text { públicas }\end{array}$ & $\begin{array}{c}\mathbf{N}^{0} \text { escuelas } \\
\text { particulares }\end{array}$ & $\begin{array}{c}\mathbf{N}^{0} \text { escuelas } \\
\text { entidades } \\
\text { religiosas }\end{array}$ & $\begin{array}{c}\text { Total } \\
\text { escuelas }\end{array}$ & $\begin{array}{l}\text { \% escuelas } \\
\text { públicas por } \\
\text { habitante }\end{array}$ \\
\hline Burgos & 333.356 & 1.179 & 48 & 26 & 1.253 & 0,35 \\
\hline León & 348.756 & 1.039 & 24 & & 1.063 & 0,30 \\
\hline Álava & 96.398 & 250 & 23 & & 273 & 0,26 \\
\hline Guadalajara & 199.088 & 477 & 23 & & 386 & 0,20 \\
\hline Teruel & 238.628 & 488 & 6 & 11 & 505 & 0,20 \\
\hline Palencia & 185.970 & 363 & 23 & & 386 & 0,20 \\
\hline Navarra & 297.422 & 569 & 9 & 4 & 582 & 0,19 \\
\hline Salamanca & 263.516 & 485 & 5 & 18 & 508 & 0,18 \\
\hline Segovia & 146.839 & 261 & 65 & 2 & 328 & 0,18 \\
\hline Santander & 214.441 & 379 & 44 & 1 & 424 & 0,18 \\
\hline Cuenca & 229.959 & 393 & 5 & 5 & 403 & 0,17 \\
\hline Zamora & 249162 & 422 & 16 & & 438 & 0,17 \\
\hline Logroño & 173.812 & 294 & 12 & 3 & 309 & 0,17 \\
\hline Ávila & 164.039 & 272 & 19 & 1 & 292 & 0,17 \\
\hline Huesca & 257.839 & 392 & 5 & 12 & 409 & 0,15 \\
\hline Oviedo & 524.529 & 729 & 101 & & 830 & 0,14 \\
\hline Valladolid & 244.023 & 328 & 78 & 6 & 412 & 0,13 \\
\hline Zaragoza & 384.176 & 473 & 26 & 19 & 518 & 0,12 \\
\hline Castellón & 260.919 & 290 & 28 & 2 & 320 & 0,11 \\
\hline Orense & 371.818 & 413 & 8 & 2 & 423 & 0,11 \\
\hline Cáceres & 302.134 & 328 & 33 & 2 & 363 & 0,11 \\
\hline Valencia & 606.608 & 653 & 125 & 38 & 816 & 0,11 \\
\hline Ciudad Real & 244.328 & 262 & 30 & 13 & 305 & 0,11 \\
\hline Vizcaya & 160.579 & 155 & 43 & 1 & 199 & 0,10 \\
\hline Toledo & 328.755 & 311 & 140 & & 451 & 0,09 \\
\hline Albacete & 201.118 & 188 & 12 & 1 & 201 & 0,09 \\
\hline Lérida & 306.994 & 282 & 27 & 9 & 318 & 0,09 \\
\hline Guipúzcoa & 156.493 & 136 & 26 & 1 & 163 & 0,09 \\
\hline Alicante & 378.958 & 311 & 37 & 2 & 350 & 0,08 \\
\hline Tarragona & 320.593 & 250 & 150 & 17 & 417 & 0,08 \\
\hline Coruña & 551.989 & 425 & 131 & & 556 & 0,08 \\
\hline Badajoz & 404.981 & 263 & 92 & 4 & 359 & 0,06 \\
\hline Granada & 444.629 & 286 & 90 & & 376 & 0,06 \\
\hline Madrid & 475.785 & 300 & 175 & 71 & 546 & 0,06 \\
\hline Huelva & 174.391 & 109 & 123 & 2 & 234 & 0,06 \\
\hline Jaén & 345.879 & 209 & 50 & & 259 & 0,06 \\
\hline Gerona & 310.970 & 177 & 31 & 30 & 238 & 0,06 \\
\hline
\end{tabular}


ANTONio J. DAZA Sierra

¿Rehabilitar patrimonio o escolarizar a la población? Gasto público en la Sevilla de mediados del siglo XIX

\begin{tabular}{|l|c|c|c|c|c|c|}
\hline Provincia & $\mathbf{N}^{\mathbf{0}}$ habitantes & $\begin{array}{c}\mathbf{N}^{\mathbf{0}} \text { escuelas } \\
\text { públicas }\end{array}$ & $\begin{array}{c}\mathbf{N}^{\mathbf{0}} \text { escuelas } \\
\text { particulares }\end{array}$ & $\begin{array}{c}\mathbf{N}^{\mathbf{0}} \text { escuelas } \\
\text { entidades } \\
\text { religiosas }\end{array}$ & $\begin{array}{c}\text { Total } \\
\text { escuelas }\end{array}$ & $\begin{array}{c}\text { \% escuelas } \\
\text { públicas por } \\
\text { habitante }\end{array}$ \\
\hline Baleares & 262.893 & 147 & 47 & & 194 & 0,06 \\
\hline Córdoba & 351.536 & 193 & 80 & 15 & 288 & 0,05 \\
\hline Almería & 315.536 & 167 & 31 & & 198 & 0,05 \\
\hline Málaga & 451.406 & 238 & 82 & 3 & 323 & 0,05 \\
\hline Canarias & 234.046 & 117 & 20 & & 137 & 0,05 \\
\hline Sevilla & 463.486 & 230 & 180 & 5 & 415 & 0,05 \\
\hline Barcelona & 713.734 & 334 & 168 & 85 & 587 & 0,05 \\
\hline Pontevedra & 428.886 & 185 & 41 & 5 & 231 & 0,04 \\
\hline Murcia & 380.969 & 156 & 41 & & 197 & 0,04 \\
\hline Cádiz & 390.192 & 128 & 141 & 3 & 272 & 0,03 \\
\hline Lugo & 424.186 & 111 & 900 & & 1.011 & 0,03 \\
\hline
\end{tabular}

Fuente: elaboración propia a partir de datos INE 1855

En este periodo histórico la oferta de escuelas a cargo de Congregaciones y Comunidades Religiosas no tuvo un papel determinante, las desamortizaciones en los años 1836 de Mendizábal y 1855 de Madoz terminaron por configurar la estructura económica, social y política.

En la segunda mitad del siglo XIX es cuando la Iglesia Católica fue uno de los protagonistas activos en la asistencia social siendo una muestra "Las Hermanas de la Caridad de San Vicente Paúl”, "Hospital de San Juan de Dios", "Hospital de los Venerables Sacerdotes", "Hospital de San Bernardo", "Beaterio de la Santísima Trinidad", "Casa de Arrepentidas", "Asilo de Ancianos de las Hermanitas de los Pobres", “Asilo de niños desamparados", "Hermanas de la Cruz”, entre otras ${ }^{31}$.

Como se observa en el cuadro 3, la ciudad de Sevilla tenía en 1855 el mayor desvío de fondos disponibles en Instrucción Primaria. No se utilizaron todos los recursos disponibles para tal fin, y se fue destinando gran parte a actividades de mantenimiento de edificios desamortizados incumpliendo de forma sistemática el número de escuelas que debían tener disponibles según la normativa vigente.

La promulgación en 1844 de la Real Orden de 2 de abril por la que se funda la Comisión Central de Monumentos determinaba obligaciones respecto al patrimonio

\footnotetext{
${ }^{31}$ C. Giménez "A short history of social welfare organizations in Seville, from their foundation still 1900”. Revista de Historia Contemporánea Hispania Nova 6, 2006.
} 
histórico que se realizaron en Sevilla con cargo a los presupuestos municipales dentro del capítulo de Instrucción Primaria.

Los motivos de la baja alfabetización no eran sólo debidos a la falta de escuelas, igual ocurría con los propios costes de oportunidad que conllevaba asistir a ellas. La escolarización sólo era gratuita para los niños más pobres y estando el trabajo infantil instaurado como una práctica generalizada el citado coste de oportunidad era muy elevado. Especialmente para las familias con menos recursos que necesitaban el jornal infantil para su subsistencia.

Estas circunstancias eran más impactantes aún en el sur por la especialización productiva agraria en cultivos extensivos de secano como el cereal y el olivar donde la oferta de mano de obra era superior a la demanda. Las inversiones en regadíos, maquinaria o el uso de fertilizantes no se llevaron a cabo en este período ${ }^{32}$.

Cuadro 3. \% de inversión en salarios y material escolar de los fondos disponibles, 1855

\begin{tabular}{|l|c|r|r|r|r|r|}
\hline Provincias & \multicolumn{1}{|l|}{$\begin{array}{l}\text { No escuelas } \\
\text { públicas }\end{array}$} & $\begin{array}{l}\text { Gastos } \\
\text { personales }\end{array}$ & $\begin{array}{l}\text { Gastos } \\
\text { materiales }\end{array}$ & $\begin{array}{l}\text { Total } \\
\text { Gastos }\end{array}$ & $\begin{array}{l}\text { Recursos } \\
\text { totales }\end{array}$ & $\begin{array}{l}\text { \%astos } \\
\text { sobre } \\
\text { recursos }\end{array}$ \\
\hline Sevilla & 230 & 693.014 & 186.779 & 879.793 & 1.513 .602 & 58,13 \\
\hline Logroño & 294 & 433.665 & 57.278 & 490.943 & 754.334 & 65,08 \\
\hline Córdoba & 193 & 475.672 & 67.168 & 542.840 & 797.045 & 68,11 \\
\hline Segovia & 261 & 290.077 & & 290.077 & 420.615 & 68,96 \\
\hline Gerona & 177 & 579.388 & 145.048 & 724.436 & 1.035 .763 & 69,94 \\
\hline Huelva & 109 & 274.633 & 64.464 & 339.097 & 454.571 & 74,60 \\
\hline León & 1.039 & 519.244 & 160.640 & 679.884 & 893.224 & 76,12 \\
\hline Valencia & 653 & 1.131 .991 & 24.291 & 1.156 .282 & 1.508 .633 & 76,64 \\
\hline Granada & 286 & 545.551 & 64.667 & 610.218 & 789.035 & 77,34 \\
\hline Soria & 562 & 401.910 & 63.700 & 465.610 & 598.837 & 77,75 \\
\hline Madrid & 300 & 820.723 & 451.858 & 1.272 .581 & 1.632 .105 & 77,97 \\
\hline Ciudad Real & 262 & 475.553 & 103.184 & 578.737 & 738.643 & 78,35 \\
\hline Ávila & 272 & 352.698 & 41.070 & 393.768 & 501.069 & 78,59 \\
\hline Santander & 379 & 566.243 & 125.660 & 691.903 & 849.683 & 81,43 \\
\hline Guadalajara & 477 & 727.177 & 180.200 & 907.377 & 1.112 .043 & 81,60 \\
\hline Burgos & 1.179 & 529.315 & 70.233 & 599.548 & 724.491 & 82,75 \\
\hline
\end{tabular}

32 A. Bernal, La propiedad de la tierra y las luchas agrarias andaluzas. (Barcelona: Editorial Ariel, 1974). 
Antonio J. DAZA Sierra

¿Rehabilitar patrimonio o escolarizar a la población? Gasto público en la Sevilla de mediados del siglo XIX

\begin{tabular}{|c|c|c|c|c|c|c|}
\hline Provincias & $\begin{array}{l}N^{0} \text { escuelas } \\
\text { públicas }\end{array}$ & $\begin{array}{l}\text { Gastos } \\
\text { personales }\end{array}$ & $\begin{array}{l}\text { Gastos } \\
\text { materiales }\end{array}$ & $\begin{array}{l}\text { Total } \\
\text { Gastos }\end{array}$ & $\begin{array}{l}\text { Recursos } \\
\text { totales }\end{array}$ & $\begin{array}{l}\text { \% Gastos } \\
\text { sobre } \\
\text { recursos }\end{array}$ \\
\hline Huesca & 392 & 608.341 & 4.978 & 613.319 & 734.867 & 83,46 \\
\hline Jaén & 209 & 542.862 & 73.141 & 616.003 & 737.692 & 83,50 \\
\hline Almería & 167 & 364.961 & 59.791 & 424.752 & 504.093 & 84,26 \\
\hline Zaragoza & 473 & 857.320 & & 857.320 & 1.009 .771 & 84,90 \\
\hline Cádiz & 128 & 580.069 & 272.742 & 852.811 & 1.000 .586 & 85,23 \\
\hline Málaga & 238 & 670.336 & 208.777 & 879.113 & 1.021 .804 & 86,04 \\
\hline Lugo & 111 & 198.254 & 41.400 & 239.654 & 278.377 & 86,09 \\
\hline Palencia & 363 & 349.417 & 96.440 & 445.857 & 507.599 & 87,84 \\
\hline Coruña & 425 & 410.948 & 109.453 & 520.401 & 586.696 & 88,70 \\
\hline Albacete & 188 & 388.838 & 30.162 & 419.000 & 467.621 & 89,60 \\
\hline Guipúzcoa & 136 & 273.534 & 28.533 & 302.067 & 332.850 & 90,75 \\
\hline Toledo & 311 & 698.620 & 118.245 & 816.865 & 888.570 & 91,93 \\
\hline Zamora & 422 & 465.199 & 45.584 & 510.783 & 541.033 & 94,41 \\
\hline Baleares & 147 & 214.534 & 53.163 & 267.697 & 283.501 & 94,43 \\
\hline Castellón & 290 & 437.358 & 26.218 & 463.576 & 487.092 & 95,17 \\
\hline Lérida & 282 & 417.517 & 194.480 & 611.997 & 627.252 & 97,57 \\
\hline Barcelona & 334 & 760.198 & 386.409 & 1.146 .607 & 1.169 .328 & 98,06 \\
\hline Canarias & 117 & 230.989 & 31.200 & 262.189 & 266.420 & 98,41 \\
\hline Tarragona & 250 & 582.601 & 96.509 & 679.110 & 688.555 & 98,63 \\
\hline Orense & 413 & 282.083 & 40.124 & 322.207 & 321.207 & 100,31 \\
\hline Valladolid & 328 & 553.802 & 221.500 & 775.302 & 768.855 & 100,84 \\
\hline Cáceres & 328 & 795.279 & 210.857 & 1.006 .136 & 990.365 & 101,59 \\
\hline Salamanca & 485 & 664.385 & 176.140 & 840.525 & 822.741 & 102,16 \\
\hline Alicante & 311 & 679.150 & 257.638 & 936.788 & 895.503 & 104,61 \\
\hline Vizcaya & 155 & 391.085 & 30.845 & 421.930 & 402.608 & 104,80 \\
\hline Oviedo & 729 & 687.998 & 52.986 & 740.984 & 702.322 & 105,50 \\
\hline Badajoz & 263 & 754.622 & 287.205 & 1.041 .827 & 971.805 & 107,21 \\
\hline Pontevedra & 185 & 273.333 & 155.649 & 428.982 & 388.862 & 110,32 \\
\hline Cuenca & 393 & 557.921 & 314.856 & 872.777 & 753.646 & 115,81 \\
\hline Teruel & 488 & 698.136 & 215.008 & 913.144 & 747.335 & 122,19 \\
\hline Murcia & 156 & 555.207 & 328.753 & 883.960 & 536.493 & 164,77 \\
\hline Navarra & 569 & 1.133 .298 & 113.499 & 1.246 .797 & 356.012 & 350,21 \\
\hline Álava & 250 & 249.425 & 40.480 & 289.905 & 32.751 & 885,18 \\
\hline Total & 16.709 & 26.144 .474 & 6.129 .005 & 32.273 .479 & 35.147 .905 & 91,82 \\
\hline
\end{tabular}

Fuente: INE Escuelas de primera enseñanza existentes en 1855, y sus gastos de personal y material. Anuario 1858. 
La suma de los recursos totales provenía de tres fuentes de ingresos: municipalidades, fundaciones y los aportados por los padres de los alumnos. En Sevilla se emplearon en gastos de personal y material tan sólo un 58,13\%. Los incrementos presupuestarios en el caso de Sevilla, como hemos señalado, no se realizaron como complemento de medidas para equilibrar el déficit de escuelas existentes, o el incremento del número de maestros, sino por el gasto en edificios que habían sido conventos y que se habían abandonado como consecuencia de la desamortización de Mendizábal.

La inversión a cargo de particulares se costeaba con fondos de cada familia que poseía capacidad económica para permitírselo, mientras la escuela pública era gratuita para las clases pobres que lo acreditasen, los llamados "pobres de solemnidad" 33.

\section{Cuadro 4. Provincias con mayores aportaciones en reales por parte de su alumnado, 1855}

\begin{tabular}{|l|r|l|r|}
\hline \multicolumn{2}{|l|}{ En términos absolutos } & Aportaciones en función del no de escuelas \\
\hline Navarra & 288206 & Gerona & 1563 \\
\hline Gerona & 276600 & Sevilla & 1191 \\
\hline Sevilla & 273836 & Cádiz & 1064 \\
\hline Cáceres & 248174 & Huelva & 886 \\
\hline Santander & 226127 & Cáceres & 757 \\
\hline León & 213340 & Málaga & 724 \\
\hline Guadalajara & 204666 & & \\
\hline Valladolid & 180000 & & \\
\hline Málaga & 172410 & & \\
\hline
\end{tabular}

Fuente: INE Escuelas de primera enseñanza existentes en 1855, y sus gastos de personal y material. Anuario 1858. Fondo documental.

Respecto al importe aportado por los alumnos Sevilla era la tercera ciudad en cuanto a capital desembolsado ascendiendo a 273.836 reales. Aportaban cantidades superiores en otros lugares como Navarra, pero para un número de escuelas muy superior, 569 escuelas frente a 230 existentes en toda la provincia de Sevilla. El caso de Gerona en esta época es muy similar en cuanto a recursos aportados por los alumnos coincidiendo en los datos anteriormente referidos de la evolución de la alfabetización en

\footnotetext{
${ }^{33}$ AHMS 4 de mayo de 1858.
} 
Cataluña que despega posteriormente frente a Castilla-León. Los gastos que aportaban los alumnos en Sevilla eran los terceros más elevados de España, pero si tenemos en cuenta las aportaciones en función del número de escuelas existentes ascendían a la segunda posición a nivel nacional tan sólo superados por Gerona, sesgando los que podían asistir a las escuelas de instrucción primaria.

\section{LA REFORMA MON-SANTILLÁN Y SUS PRIMEROS EFECTOS 1846-1850}

Las medidas impulsadas por Alejandro Mon fueron inicialmente encaminadas a evitar la bancarrota de la Hacienda, y a dotarla de liquidez, al tiempo que se pretendía alcanzar permanentemente el equilibro presupuestario a nivel municipal. La reforma tributaria y el arreglo de la deuda intentaban evitar el déficit en las cuentas estatales y atender las obligaciones contraídas, en aras de bajar la presión de los tipos de interés, y tener acceso a los mercados financieros.

Partiendo de esta premisa anterior, el siguiente paso de la Hacienda fue ceder a las oligarquías locales el reparto y la recaudación de la contribución en los municipios. En paralelo, los terratenientes españoles frenaron en 1845 la realización de un catastro que permitiese medir la base imponible y la creación de un cuerpo de funcionarios para gestionar el tributo ${ }^{34}$.

En 1844 solo había dos escuelas públicas en Sevilla, una de niños y otra de niñas. El Ayuntamiento de la ciudad, incumplía la ley de 21 de julio de 1838 promulgada para plantear provisionalmente el plan de instrucción primaria ${ }^{35}$, como puso de manifiesto la carta fechada el 8 de noviembre de 1845 enviada al Ayuntamiento emitiendo un informe al Jefe Político ${ }^{36}$.

\footnotetext{
${ }^{34}$ F. Comín "La corrupción permanente: el fraude fiscal en España". Revista de Historia Contemporánea Hispania Nova, 2018, número 16, pp. 481-521.

${ }^{35}$ Ley Someruelos, y su posterior desarrollo a través del Reglamento de Escuelas Públicas de Instrucción Primaria de 26 de noviembre de 1838, conocido como Reglamento Montesino.

${ }^{36}$ AHMS. Hacienda/Presupuestos. Carta de 8 de noviembre de 1845 enviada por la Comisión Local de Instrucción Primaria al Ayuntamiento de la ciudad. "Es un doloroso escándalo que la primera capital de Andalucía tuviese sólo en 1844 una escuela gratuita de niños y otra de niñas y eso exclusivamente para el barrio de Triana, cuando repetidas resoluciones, que la Comisión recuerda, disponen que por cada quinientos vecinos haya una escuela pública, y de no otra suerte puede darse la primera instrucción a esa
} 
La Comisión Superior de Instrucción Primaria solicitó noticias sobre los fondos destinados al sostenimiento de las Escuelas Gratuitas, y la creación de otras nuevas, proponiendo varias en la capital y en el barrio de Triana ${ }^{37}$.

La respuesta de la Comisión Local aludía a la "insuficiencia de la financiación con los impuestos indicados"; "los aguadores", y "el impuesto en libra de carne de macho", y explicaba "la necesidad de arreglar los conventos deteriorados y los gastos necesarios para ello"38. Ante un nuevo requerimiento, la respuesta de la Comisión Local es similar, manifestando la "Imposibilidad de llevar a cabo la Academia gratuita de niñas en el Convento de San Acasio debido al estado ruinoso del edificio, (...) la imposibilidad de atender los gastos de la obra y la poca utilidad que produciría el establecimiento de una escuela gratuita en uno de los barrios más ricos de la ciudad”. También se aludía a que "el Convento de los Menores fue ocupado por la Guardia Civil, hecho que ha impedido la apertura de la Escuela Gratuita”,39.

Descripción en el mapa de las ubicaciones de las escuelas existentes en 1820 Diez escuelas para niños pobres ubicadas en sus respectivos cuarteles.

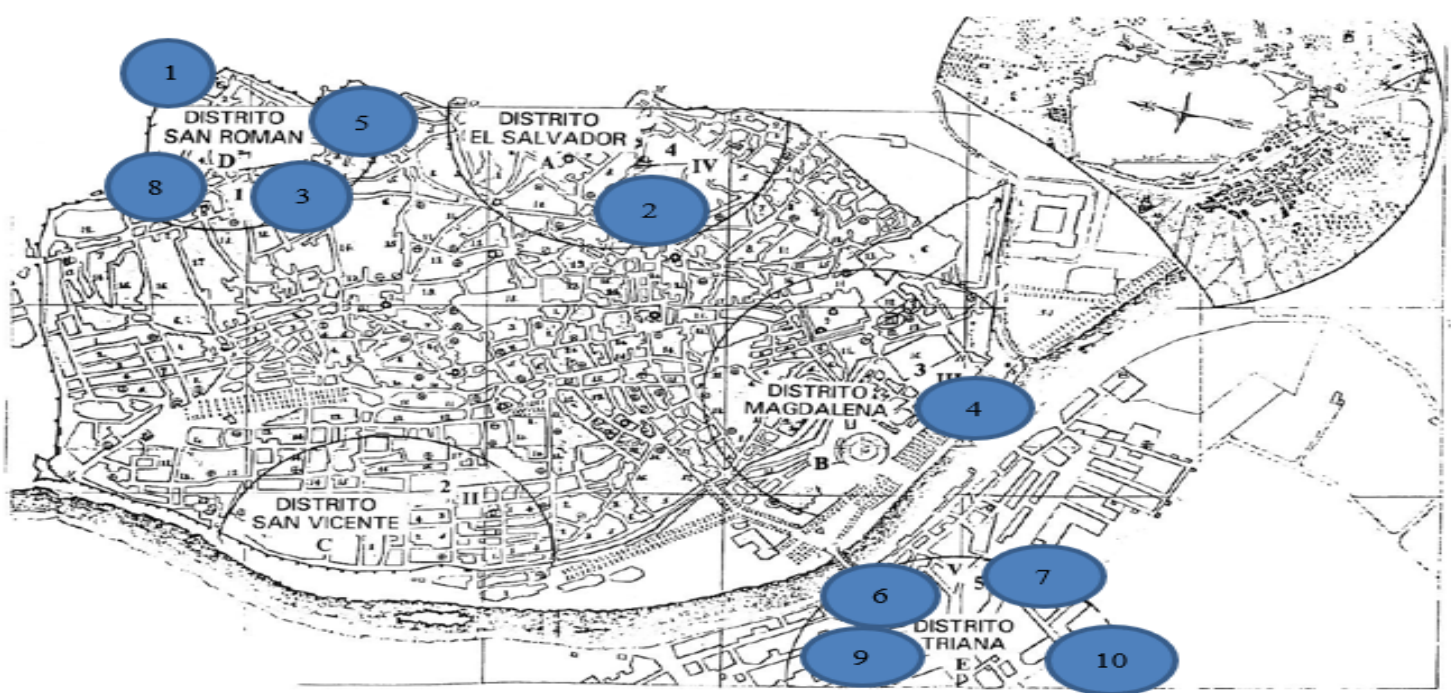

Fuente: elaboración propia siguiendo a Aguilar (1973, p. 61) y Collado (1985, p.144). Notas: (1) Teniendo en cuenta la división realizada por Pablo de Olavide, asistente de Sevilla nombrado por Carlos III (según Cédula de 13 de agosto de 1769, AHMS), Sevilla tenía 501 manzanas con 11,722 casas. (2) La relación de las diez escuelas a beneficio de los pobres era la siguiente: (1) San Luis, fundación piadosa

multitud de jóvenes de ambos sexos, que en Sevilla existe carencia de los elementos más indispensables para desenvolver su razón y hacerse útiles a si propios y a la patria..."

37 AHMS Comisión Local de Instrucción Primaria. Acta de 7 de abril de 1846.

38 AHMS Comisión Local de Instrucción Primaria. Acta de 7 de abril de 1846.

39 AHMS Comisión Local de Instrucción Primaria. Acta de 21 de julio de 1847. 
llevada a cabo por Nicolás de Robles y su esposa Dionisia de Encinas, la exclaustración y posterior desamortización de Mendizábal traspasa la propiedad a la Diputación; (2) Colegio del Santo Ángel (desamortizado en 1835, uso posterior civil o militar); (3) Colegio San Francisco de Paula (exclaustrado y desamortizado en 1835, uso posterior civil o militar); (4) Convento de San Agustín (desamortizado en 1835, uso posterior civil o militar); (5) Santísima Trinidad de la Calzada (exclaustrado y desamortizado en 1835, uso posterior civil o militar); (6 y 7) San Jacinto (desamortizado en 1835, en 1844 se construye un teatro); (8) Santo Tomás de Aquino (cerrado con la desamortización de 1835, usos civiles y militares); (9) Calle Larga de Triana (desaparecido en 1835, se convierte nuevamente en colegio en 1890 tras levantarse en el solar que antiguamente ocupaba; (10) Calle Castilla de Triana (desaparecido).

La mayoría de estos edificios que se querían volver a activar eran los que en el período absolutista habían sido sede de escuelas. Las diez escuelas gratuitas que había en la ciudad en 1820 estaban situadas en conventos que habían sido posteriormente desamortizados. Sus alumnos eran llamados "pobres de solemnidad".

Se deducen varias cuestiones: la primera es la realidad patente de la imposibilidad de llevar a cabo la tarea con los impuestos asignados. La segunda, es el desgaste presupuestario que suponía arreglar los conventos con cargo a la instrucción primaria. El espíritu de la ley se quebrantaba porque se detraían fondos destinados a la instrucción primaria para rehabilitar conventos desamortizados. Una de las causas que motivaba el drenaje de los presupuestos previstos para la instrucción primaria era la obligación de seguir las pautas marcadas por la Comisión de Monumentos Históricos Artísticos (CMHA).

El modelo de 1845 distinguía dos tipos de gastos: los obligatorios y los voluntarios o imprevistos. Los obligatorios comprendían diferentes partidas: Ayuntamiento, Policía Urbana y rural, Instrucción Pública, Beneficencia, Obras públicas, Corrección pública, Montes y Cargas, incluyendo las cargas partidas como la deuda con los censualistas, que fue especialmente significativa en el caso de la hacienda hispalense decimonónica, representando hasta una cuarta parte de los ingresos ${ }^{40}$. Además, incluía las deudas con la Hacienda Central, partidas previstas para el sostenimiento de la Diputación, indemnizaciones, gastos de pleitos y fiestas religiosas. Estas partidas podían ser modificadas por el Jefe Político o el Gobierno sin el consentimiento del ayuntamiento. En cuanto a los gastos voluntarios, se incluyen las obras de nueva construcción y, en los imprevistos, los gastos necesarios para hacer frente a calamidades públicas, teniendo el límite del 10\% del presupuesto. Estos gastos

\footnotetext{
${ }^{40}$ AHMS. Liquidación nominal de acreedores censualistas del año 1835. Escribanía de Cabildo, $1^{\mathrm{a}}$ Apéndice, letra C, tomo 110. La liquidación de los acreedores censualistas fue una cuestión permanente.
} 
voluntarios podían ser rechazados o reducidos por el Jefe Político o el Gobierno, pero no incrementados, para lo que se necesitaba el previo consentimiento del ayuntamiento y los mayores contribuyentes en igual número que los concejales. Por otra parte, respecto al capítulo de ingresos hay que destacar tres apartados: los ingresos ordinarios, los ingresos extraordinarios y "los medios autorizados para cubrir el déficit". Los ingresos ordinarios se componían de varias partidas; los procedentes de las fincas de propios y de los montes, a los que se les deduce el 20 por ciento, donde se incluyen también los intereses de la Deuda del Estado, y los que se recibieron en compensación por la desamortización de 1855 .

\section{Cuadro 5. Gastos presupuestados en reales por la Comisión Local de Instrucción Primaria, 1864 (primer presupuesto, 26.10.1845)}

\begin{tabular}{|l|r|}
\hline 1. Escuela de niñas y párvulos en San Pedro de Alcántara: & \\
\hline - Presupuesto de la obra necesaria para la formación de ambas escuelas y reparaciones & 38.418 \\
\hline - Para gastos de útiles & 10.000 \\
\hline 2. Escuela de niños en los Menores: & 56.900 \\
\hline - Para la reparación del Convento de los Menores y creación de escuelas. & 10.000 \\
\hline - Para gastos de útiles & 115.318 \\
\hline Total de gastos en edificios & 187.217 \\
\hline Presupuesto inicial de 1846 (26.10.1845) & $61,6 \%$ \\
\hline Porcentaje dedicado a edificios & \\
\hline
\end{tabular}

Fuente: elaboración propia a partir de presupuestos municipales/ Hacienda 1846 (AHMS).

Los presupuestos de la Comisión Local de Instrucción Primaria año 1846 permiten profundizar en el problema de la financiación de las escuelas públicas. En un primer presupuesto (cuadro 5), se preveía una inversión en Instrucción Primaria de 187.710 reales, para atender las necesidades existentes y cumplir con la ley, 61,6\% dedicado a edificios.

\section{Cuadro 6. Gastos presupuestados en reales por la Comisión Local de Instrucción Primaria, 1846 (segundo presupuesto, 25.06.1846)}

\begin{tabular}{|l|r|}
\hline 1. Obras en edificios propios del Ayuntamiento que se aplican a Instrucción Primaria & 55.318 \\
\hline $\begin{array}{l}\text { 2. Propuesta de } 10 \text { nuevas escuelas en la ciudad } \\
\text { (4 de niños, } 4 \text { de niñas, 1 de párvulos y 1 de adultos) }\end{array}$ & 134.175 \\
\hline Segundo Presupuesto de 1846 (25.06.1846) & 236.822 \\
\hline Porcentaje dedicado a edificios & $79,99 \%$ \\
\hline
\end{tabular}

Nota: este presupuesto acabó siendo rechazado debido al elevado déficit.

Fuente: elaboración propia a partir de presupuestos municipales/ Hacienda 1846 (AHMS). 
En un segundo presupuesto (cuadro 6) el Ayuntamiento elevó la partida a 236.882 reales, con un $79,99 \%$ dedicado a edificios. Tras el déficit observado, el Gobernador lo redujo a 61.175 reales, lo que representaba una disminución de un $74 \%$ sobre el anterior presupuesto. El motivo fue la negativa municipal a incrementar las contribuciones. En el presupuesto inicial expansivo de 1846 había llamado la atención el déficit de más de 1,8 millones de reales, la lucha contra el déficit era un objetivo estatal. La respuesta del Gobernador a la propuesta del Ayuntamiento solicitando proponer nuevos arbitrios fue negativa ${ }^{41}$. El Ayuntamiento culpó de la situación a las modificaciones tributarias llevadas a cabo.

El presupuesto en Instrucción Primaria se repite en el año 1847 debido a los retrasos tras las negociaciones. El planteamiento se vuelve menos ambicioso, y de las diez escuelas proyectadas se pasan a presupuestar cuatro escuelas. Como ocurría en los presupuestos anteriores, la mayor intención del gasto se destinaba a la rehabilitación de los edificios, edificios anteriormente vinculados a la iglesia y, en su mayoría, desamortizados. Esta cuestión es de una particularidad extrema en la ciudad de Sevilla, pues poseía una extensa red de conventos y patrimonio eclesiástico que había sido desamortizado. Los presupuestos corroboran que las políticas municipales, fueron encaminadas a evitar el incremento de las contribuciones, $y$, en segundo lugar, al aumento de la recaudación mediante los arbitrios.

Se realizaron grandes inversiones en antiguos conventos desamortizados para alojar las escuelas, en detrimento del salario de los maestros que veían como sus reivindicaciones no eran atendidas, (retrasos en los pagos, aumentos de sueldo, compras de libros...). Una disposición de la Dirección General, con fecha de 3 de junio de 1843, establecía la obligación de remitir cada tres meses un estado de los pagos hechos a los maestros titulares ${ }^{42}$. La Comisión Superior, dependiente de las Diputación, bajo el mandato del Jefe Político, fiscalizaba al Ayuntamiento.

\footnotetext{
${ }^{41}$ AHMS. Documentación para la formación del presupuesto de 1846. Correspondencia al Jefe Político por parte del Ayuntamiento y su respuesta. Carta del Vicepresidente del Consejo del Excelentísimo Ayuntamiento Constitucional de Sevilla, Sr Ibarra, con fecha de 7 de julio de 1846, donde indica "remitido ya al Gobierno de S.M. para su aprobación el presupuesto de gastos municipales de esta Ciudad, sólo falta que V.E. se sirva proponer los arbitrios que estime convenientes para cubrir con su importe el déficit de 1.822.013 reales que de aquel resulta".

42 AHMS Actas de la Comisión Local de Instrucción Primaria. Sesión de 26 de julio de 1846.
} 
En enero de 1848 la Comisión volvió a tratar sobre la creación de una escuela pública y gratuita, esta vez en el barrio de San Esteban, para que acudieran los muchos niños pobres de san Roque y San Esteban, el punto más abandonado de la población, y que no contaba con escuelas públicas cerca. Un oficio de la Comisión Superior informaba sobre la necesidad de crear comisiones auxiliares por barrios ${ }^{43}$.

La financiación de la Instrucción primaria remite a la construcción del entramado institucional del país, en su vertiente fiscal. A pesar de la creación de una Dirección General de Estadística de la Riqueza en 1846, cuya finalidad era censar la riqueza agrícola mediante un catastro que permitiera medir la base imponible de riqueza, los propietarios evadían los impuestos ocultando el valor de sus activos ${ }^{44}$.

La legislación que afectaba a la Administración local se promulgaba al mismo tiempo que se aprobaba la Constitución de 1845: la Ley de Ayuntamientos (1845), precedida por la Ley de Organización y Atribuciones de los Ayuntamientos (1840), y la Instrucción de Contabilidad Municipal (1846). Con la nueva legislación de 1845 el Jefe Político ganaba peso en la toma de decisiones, y con él se debatieron cuestiones acerca de la titularidad y el destino de los edificios dedicados a la Instrucción Pública ${ }^{45}$.

La Comisión Local reconoció desconocer si el presupuesto de gastos era obligatorio, y también declaraba desconocer el importe que se recaudaba por los puestos de agua que habitualmente se destinaban a la instrucción primaria. La demanda de escuelas de instrucción primaria existía, y se hacía patente en las actas. A través de las autoridades de los barrios se solicitaban escuelas, y en ocasiones los vecinos incluso se comprometían a aportar una cantidad de dinero ${ }^{46}$. Los presupuestos debían de ser remitidos al Jefe Político antes del 1 de abril del año en curso, de no hacerse se

\footnotetext{
43 AHMS. Actas Comisión Local de Instrucción primaria. Sesión del día 17 de enero de 1848.

44 G. Tortella y C. Núñez, El desarrollo de la España contemporánea, (Madrid, Alianza Editorial, 2017), pp. 227-228.

45 En 1845 el Jefe Político de Sevilla era José de Hezeta, un militar de prestigio, nacido en La Habana, que contaba con méritos de guerra en la batalla de Trafalgar y en varios episodios de la lucha contra los franceses. Levantado contra el regente Espartero, había participado en la defensa de Sevilla, lo que le hizo merecedor de la confianza de los moderados, y su nombramiento como Jefe Político de la ciudad en varios períodos.

${ }^{46}$ AHMS Sesión de 26 de agosto de 1845: "Se dio cuenta de un oficio del Comisario de Protección y Seguridad Pública del ler distrito en el que se recordaba la excitación de los vecinos de los "Húmeros, Carretera y Cestería" para que se estableciese una escuela por dichos barrios y se convocara un maestro para la retribución de 316 reales a que ascendería el donativo de los vecinos y que se encargase dicho Comisario de la cobranza de los donativos o lo delegase”.
} 
entenderían prorrogados automáticamente los del año anterior. Los presupuestos debían ser aprobados por el Jefe Político, siempre que su importe superara la cantidad de 200 mil reales ${ }^{47}$. La formación de los presupuestos iba precedida de un debate entre el Ayuntamiento y el Jefe Político respecto a la interpretación de las últimas normativas emanadas del Gobierno. Este debate se centraba en la supresión de unos arbitrios y la incorporación de otros, y en el que se ponía de manifiesto la negativa del Ayuntamiento al incremento de las contribuciones. La discusión política entre las necesidades percibidas desde el Estado central frente a los intereses personales de los grandes contribuyentes, que dirigían la Corporación Municipal, fue configurando institucionalmente la ciudad.

El Jefe Político propuso en 1849 la supresión de determinados arbitrios. Las observaciones realizadas hacían referencia a que dichos arbitrios tenían una existencia remota, estando consignados desde el reglamento del Supremo Consejo de Castilla de 1768. El Ayuntamiento apeló a los antiguos arbitrios como necesarios para cubrir las obligaciones que había contraído el mismo ${ }^{48}$.

\section{Cuadro 7. Análisis de los porcentajes de gasto entre 1846 y 1850}

\begin{tabular}{|l|r|r|r|r|r|r|}
\hline Partida & $\mathbf{1 8 4 6}$ & $\mathbf{1 8 4 6}^{*}$ & $\mathbf{1 8 4 7}$ & $\mathbf{1 8 4 8}$ & $\mathbf{1 8 4 9}$ & $\mathbf{1 8 5 0}$ \\
\hline Gastos obligatorios del Ayuntamiento & 9,1 & 11,8 & 7,7 & 7,7 & 7,4 & 12,8 \\
\hline Guardia municipal & 1,0 & 1,1 & 4,7 & 4,7 & 4,3 & 5,4 \\
\hline Policía urbana & 17,7 & 19,7 & 14,1 & 14,1 & 15,1 & 17,0 \\
\hline Instrucción Pública & 4,5 & 1,6 & 1,8 & 1,8 & 1,7 & 1,5 \\
\hline Beneficencia & 14,9 & 2,9 & 25,8 & 25,8 & 24,1 & 25,8 \\
\hline Contribuciones y otros gastos & 27,1 & 18,6 & 23,5 & 23,5 & 23,3 & 16,2 \\
\hline Corrección pública & 2,4 & 26,6 & 13,5 & 13,5 & 14,4 & 15,7 \\
\hline Obras públicas y obras de nueva construcción & 20,8 & 10,9 & 6,9 & 6,9 & 6,9 & 0,0 \\
\hline Montes e imprevistos & 2,5 & 7,1 & 2,1 & 2,1 & 2,7 & 5,6 \\
\hline Total & 100,0 & 100,0 & 100,0 & 100,0 & 100,0 & 100,0 \\
\hline
\end{tabular}

Nota (*): gastos revisados.

Fuente: elaboración propia a partir de Hacienda Presupuestos (AHMS) / Presupuestos Colección Alfabética 1180 y ss.

\footnotetext{
${ }^{47}$ AHMS. Hacienda/Presupuestos C.A. 1181. Carta de 12 de febrero de 1849 de la Comisión de Hacienda del Ayuntamiento de Sevilla que dirige al Alcalde informando de la normativa vigente en referencia al Real Decreto de 31 de enero de 1849.

${ }^{48}$ AHMS. Hacienda/Presupuestos C.A. 1181. Observaciones que se someten a la consideración del Jefe Político sobre la Carta que la Comisión de Hacienda del Ayuntamiento de Sevilla que dirige al Alcalde informando de la normativa vigente en referencia al Real Decreto de 31 de enero de 1849 con fecha 12 de febrero de 1849.
} 
La comparación de los presupuestos del Ayuntamiento entre 1846 y 1850 (cuadro 7) muestra la disminución del porcentaje de los gastos en función del total del presupuesto en Instrucción Pública (pasando del 4,5\% presupuesto inicial de 1846 al $1,5 \%$ en 1850) y el incremento de los gastos en Beneficencia (pasando del 14,9\% al 25,8\%). En una etapa de reorganización donde se estaba consolidando la nueva estructura municipal, se priorizaron cuestiones relativas al orden y configuración institucional, por lo que se incrementaron los gastos obligatorios del Ayuntamiento al tiempo que aumentaba su personal. La acción benéfica y educativa de la Iglesia Católica se estaba desmantelando, y al municipio se le asignaron estas funciones. Fueron los ingresos de los bienes de propios los que principalmente sostuvieron la beneficencia, cuyos destinos fueron fundamentalmente los Hospitales.

El inicio efectivo de la organización de Beneficencia se efectúa a partir de la Ley de 20 de junio de 1849 que crea las Juntas Provinciales de Beneficencia para el control e inspección de los establecimientos de beneficencia y de sus amplios bienes y recursos. Fueron reguladas por el Reglamento de 14 de mayo de 1852 que recogía importantes medidas, a destacar: que todos los establecimientos de beneficencia alcanzarían la consideración de públicos, salvo aquellos particulares que cumpliesen con determinados requisitos, y que la dirección de toda la Beneficencia en España quedaba en manos del Gobierno a través de una Junta General en Madrid y de las Juntas Provinciales en cada capital de provincia bajo la presidencia del Gobernador Civil ${ }^{49}$.

Los ingresos de propios del ayuntamiento de Sevilla eran productos de 464 fincas urbanas, diversas fincas rústicas y tributos que cobraban por ellas a los arrendatarios. Los destinos fueron las estancias en los diferentes hospitales existentes; Hospital Central, Pozo Santo, Venerables Sacerdotes, más los gastos necesarios para el mantenimiento del patrimonio como fueron las reparaciones de fincas urbanas, reparaciones de los hospitales, contribuciones de inmuebles, alumbrado y limpieza, tributos, capellanías, memorias, tres por ciento de gastos por los cobradores de los tributos, sueldos de los empleados municipales, sueldo del arquitecto municipal, y gastos de administración ${ }^{50}$. La desamortización de Madoz de 1855 les privaría de recursos fundamentales como fueron los bienes de propios y comunes.

\footnotetext{
${ }^{49}$ AHPSE/1.1.3.8. Junta Provincial de Beneficencia. S. XV/1986.

${ }^{50}$ AHMS. Hacienda/Presupuestos C.A. 1181
} 
Haciendo un balance de lo acontecido en el ámbito de la Instrucción Pública en la ciudad de Sevilla, entre 1846 y 1850, destacamos las siguientes cuestiones:

Los presupuestos no adecuaron la inversión en Instrucción Primaria a lo establecido legalmente, por lo tanto, no hubo un gran interés por invertir en educación.

Fue relevante para la Comisión rehabilitar los conventos, de modo que se destina un porcentaje elevado a este destino.

No se realizaron repartimientos equilibrando los presupuestos iniciales, ampliando las contribuciones, ya que se negaron los grandes contribuyentes, la mayoría terratenientes que ocupaban la administración municipal.

No se incrementaron los arbitrios para equilibrar los presupuestos.

Aumentaron los gastos en personal y en Beneficencia, siendo significativo que incluso el gasto en celadores superó al de Instrucción Pública.

\section{LAS INJERENCIAS DEL JEFE POLÍTICO Y LA COMISIÓN SUPERIOR: LAS ACTAS DE LA COMISIÓN LOCAL ENTRE 1851 Y 1854.}

El periodo que se inicia en 1851 mostró una tendencia diferente, donde las exigencias de la Comisión Superior y el Gobernador impulsaron el cumplimiento de la ley referente al número de escuelas. En consecuencia, debían realizarse mayores inversiones, no solo las necesarias en Instrucción Primaria, sino adecuar las infraestructuras de la ciudad ante la presión migratoria procedente del campo. En la década de los años cincuenta se produjo la destrucción de las murallas, y se invirtió en las obras de abastecimiento de agua a la ciudad, todo con el propósito de evitar los graves problemas que existían respecto a la higiene y que se ponían de manifiesto con diferentes epidemias. El debate ya no iba a ser sobre ampliar los presupuestos de gastos, ya que las instituciones eran conscientes de la necesidad, sino la forma de financiar los presupuestos. Las opciones eran incrementar los consumos, o incrementar los recargos sobre las contribuciones territorial e industrial, a lo que se oponían los grandes contribuyentes, que a su vez controlaban las corporaciones municipales.

El resultado fue el cambio de una hacienda patrimonial basada en los ingresos de propios a una hacienda fiscal, donde los consumos ostentaron un mayor protagonismo en la estructura presupuestaria. El elevado déficit del presupuesto de 1850 planteado al 
Jefe Político y trasladado al Ministerio vino corregido proponiendo un incremento de las contribuciones, a lo que se negó el Ayuntamiento. Se propuso incrementar los ingresos de contribuciones de inmuebles, cultivos, ganadería, industria y comercio, entre otras partidas; conviene subrayar que los grandes contribuyentes eran los que decidían los cupos y los amillaramientos. Esta negativa a incrementar las contribuciones corrobora el papel relevante de los grupos de presión a la hora de velar por sus respectivos intereses como una variable determinante para el cálculo de la base imponible del sujeto pasivo ${ }^{51}$. En este proceso, se estimaba que la ocultación de tierras en Andalucía a efectos tributarios estaba entre el $28 \%$ en Cádiz y por encima del $100 \%$ en Córdoba". Los oligarcas de los pueblos y capitales se hicieron con el control. ${ }^{52}$

Se trataba de un impuesto de cupo, donde la responsabilidad era colectiva, y fue un instrumento utilizado para defraudar y trasladar la responsabilidad de la carga fiscal, de manera que la riqueza imponible se adaptó a los cupos y no al revés. También era frecuente la corrupción en los agentes que se encargaban de la recaudación, de modo que se bajaba el cupo a determinados municipios tras cobrar comisiones por ello ${ }^{53}$. El impuesto sobre la tierra en el periodo 1850-1890 aumentó en un 112 por 100, mientras la recaudación general aumentó un 134 por 100, a pesar del enorme incremento en la puesta en explotación de tierras por el esfuerzo desamortizador. Los mayores fraudes provenían de las grandes propiedades, ya que tan solo estas tenían acceso al poder político, tanto en Madrid como en el Ayuntamiento, y además debido al tamaño de las extensiones eran más difíciles de medir ${ }^{54}$.

El nuevo sistema fiscal reforzó los ingresos del Estado, suavizó los déficits precedentes, pero no logró el total equilibrio fiscal. La fase de gestión tributaria quedó

\footnotetext{
${ }^{51}$ AHMS. Hacienda/Presupuestos C.A. 1181. Observaciones que se someten a la consideración del Jefe Político sobre la carta que la Comisión de Hacienda del Ayuntamiento de Sevilla dirige al Alcalde informando de la normativa vigente en referencia al Real Decreto de 31 de enero de 1849 , con fecha 12 de febrero de 1849. AHMS. Hacienda/Presupuestos C.A. 1181. Presupuesto de 1850 enviado al Jefe Político con fecha 1 de marzo de 1849.

${ }^{52}$ R. Vallejo "Los amillaramientos como fuente estadística: una visión crítica desde la contribución territorial". Revista Historia Agraria 20, 2000, pp. 110.

${ }^{53}$ R. Vallejo "Los amillaramientos como fuente estadística: una visión crítica desde la contribución territorial". Revista Historia Agraria 20, 2000, pp. 115.

${ }^{54}$ G. Tortella y C. Núñez, El desarrollo de la España contemporánea, (Madrid, Alianza Editorial, 2017), pp. 230.
} 
en manos de las corporaciones locales y por este cauce entraron poderosos enemigos, como el fraude fiscal y la arbitrariedad en la distribución de los impuestos ${ }^{55}$.

El presupuesto de 1851 en Instrucción Pública supuso un incremento del 0,70\% con relación a 1850 hasta alcanzar la cantidad de 96.550 reales (2,2\%) (cuadro 8). La mayor recaudación vino motivada por el incremento de los arbitrios y derechos establecidos. El déficit presupuestario se redujo en más de medio millón de reales en 1850-51. En 1852, el gasto en Instrucción Pública se situó en 117.308 reales, un 21,5\% más que el año anterior, y fue soportado por los arbitrios. Coincide con el mandato del alcalde José María Rincón (1851-54), quien había sido miembro de la Comisión Local de Instrucción Primaria y había creado en 1849 la Inspección de la Enseñanza Primaria $^{56}$.

A diferencia de años anteriores, se planteó un presupuesto equilibrado entre ingresos y gastos. Las partidas de ingresos que sufrieron cambios más significativos fueron los Arbitrios y Derechos Establecidos, que aumentaron un 13\%. Los Productos Extraordinarios también tuvieron un notable incremento, pasando desde los 30 mil reales (1851) a 250 mil reales (1852). El incremento del gasto en Instrucción Pública vino dado por el aumento del número de alumnos -quinientos- en las Escuelas Pías de San Luis, y del número de escuelas vía arrendamiento de inmuebles e incremento de medios, así como material escolar y dotaciones de premios. La expansión del gasto público municipal en instrucción primaria estuvo precedida de una mayor regulación jurídica, con la introducción de cambios normativos tendentes a una mayor concreción de la norma y a un refuerzo y/o creación de la inspección educativa impulsada desde la Administración central del Estado a raíz del Real Decreto de 30 de marzo de $1849^{57}$.

Los presupuestos de 1853 se sustentaron en unos ingresos cuantificados en 5.045.907 reales -los ingresos de propios ascendieron a 357.155 reales y los arbitrios a 3.473.641 reales- frente a 5.505.926 reales de gastos, produciendo un déficit de 460 mil

\footnotetext{
55 F. Comín, P. Martín, y R. Vallejo. La Hacienda por sus ministros. La etapa liberal de 1845 a 1899 , (Prensas Universitarias de Zaragoza, Zaragoza, 2006), pp. 73-75.

56 AHMS. Hacienda/ Presupuestos Colección alfabética 1181 año 1851.

${ }^{57}$ La inspección fue impulsada durante el mandato de Gil de Zárate como director general de Instrucción Pública (1846-1851). Tras el Real Decreto se promulgó el Reglamento de inspectores de 15 de mayo y la Orden de 12 de octubre sobre las visitas.
} 
reales. El gasto en Instrucción Primaria supuso un 2,2\% sobre el total de los gastos empleados, prácticamente el mismo porcentaje que el año anterior.

\section{Cuadro 8. Presupuestos municipales en reales, 1850-54}

\begin{tabular}{|l|r|r|r|r|r|}
\hline Conceptos presupuestarios & $\mathbf{1 8 5 0}$ & $\mathbf{1 8 5 1}$ & $\mathbf{1 8 5 2}$ & $\mathbf{1 8 5 3}$ & $\mathbf{1 8 5 4}$ \\
\hline Gastos obligatorios & 561.775 & 522.775 & 500.301 & $\mathrm{Nd}$ & 328.605 \\
\hline Policía seguridad & 236.160 & 177.000 & 187.000 & $\mathrm{Nd}$ & 192.200 \\
\hline Policía urbana & 745.145 & 785.145 & 880.145 & $\mathrm{Nd}$ & 922.710 \\
\hline Instrucción pública & 64.940 & 96.550 & 117.308 & 121.473 & 132.283 \\
\hline Beneficencia & 1.127 .275 & 1.000 .918 & 1.052 .683 & $\mathrm{Nd}$ & 1.197 .302 \\
\hline Obras públicas & 707.920 & 1.050 .449 & 1.063 .000 & $\mathrm{Nd}$ & 1.606 .500 \\
\hline Corrección pública & no aplicable & no aplicable & no aplicable & no aplicable & 132.264 \\
\hline Cargas y montes & 687.555 & 637.321 & 744.144 & $\mathrm{Nd}$ & 746.188 \\
\hline Imprevistos & 243.279 & 160.000 & 128.193 & $\mathrm{Nd}$ & 100.000 \\
\hline Gastos voluntarios & $\mathrm{Nd}$ & $\mathrm{nd}$ & 171.542 & $\mathrm{Nd}$ & $\mathrm{nd}$ \\
\hline Presupuesto año anterior & no aplicable & no aplicable & no aplicable & no aplicable & 189.364 \\
\hline Total Gastos & 4.374 .049 & 4.430 .158 & 4.844 .316 & 5.505 .926 & 5.547 .416 \\
\hline Total Ingresos & 3.670 .200 & 4.239 .226 & 4.844 .316 & 5.045 .907 & $\mathrm{nd}$ \\
\hline Déficit & -703.849 & -190.932 & 0 & -460.019 & $\mathrm{nd}$ \\
\hline$\%$ Instrucción Pública / Total Gastos & 1,5 & 2,9 & 2,4 & 2,2 & 2,3 \\
\hline
\end{tabular}

Fuente: Presupuestos/ Hacienda año s 1850-1854 (AHMS).

En la sesión de 13 de abril de 1853 se indicaba que las obras de San Hermenegildo estaban finalizando y que se debían ir reparando los útiles para la docencia $^{58}$. Igualmente, en 1853 la cuestión de la enseñanza en adultos volvió a replantearse, valorándose el nuevo proyecto de la Comisión que proponía al Ayuntamiento, la apertura de un curso de enseñanza para adultos, estableciéndose a tales efectos, dos escuelas: una en los Menores (Convento de los Menores) y otra en San Jacinto (Convento de San Jacinto). Todo apunta a que los gastos en estos edificios religiosos pudieron haber comprometido en gran medida los presupuestos ${ }^{59}$. Vuelve a plantearse el alquiler de inmuebles debido al mal estado de las escuelas. ${ }^{60}$ En principio, ambas escuelas debieron repartirse el presupuesto disponible. En este contexto, no resulta sorprendente que el déficit se incrementara en más de 450 mil reales. En 1854 el gasto en Instrucción Pública aumentó notablemente, casi un $9 \%$ con respecto al año anterior.

\footnotetext{
58 AHMS. Actas Comisión Local de Instrucción primaria. Sesión del día 13 de abril de 1853.

59 AHMS Sesión de 21 de mayo de 1853.

${ }^{60}$ AHMS. Sesión de 4 de junio de 1854. "Niñas de Santa Florentina, urgente la búsqueda de otro edificio." Este nuevo arrendamiento supuso un coste diario aproximado de 8-10 reales.
} 
Antonio J. DAZA Sierra

¿Rehabilitar patrimonio o escolarizar a la población? Gasto público en la Sevilla de mediados del siglo XIX

\section{Cuadro 9. Presupuestos municipales en reales, 1850-54. Evolución Instrucción Pública (valores absolutos y porcentaje sobre el total del gasto)}

\begin{tabular}{|l|r|r|r|r|r|}
\hline Conceptos presupuestarios & $\mathbf{1 8 5 0}$ & $\mathbf{1 8 5 1}$ & $\mathbf{1 8 5 2}$ & $\mathbf{1 8 5 3}$ & $\mathbf{1 8 5 4}$ \\
\hline Instrucción pública & 64.940 & 96.550 & 117.308 & 121.473 & 132.283 \\
\hline \% Instrucción Pública / Total Gastos & 1,5 & 2,9 & 2,4 & 2,2 & 2,3 \\
\hline
\end{tabular}

Fuente: Presupuestos/ Hacienda año s 1850-1854 (AHMS).

Mientras el incremento de los arbitrios se triplicó en diez años, el gasto en Instrucción Primaria municipal apenas se duplicó entre los años 1850 a 1854. Sevilla sólo empleó un 58\% en gastos de personal y material, el $42 \%$ restante se destinó a la rehabilitación de los edificios ${ }^{61}$. El leve incremento que se llevó a cabo en las partidas destinadas a Instrucción Primaria pública lo soportaron los arbitrios, que pesaban sobre las clases más débiles.

Gráfico 1. Evolución de los ingresos por Propios, Arbitrios y beneficencia, 1844-56

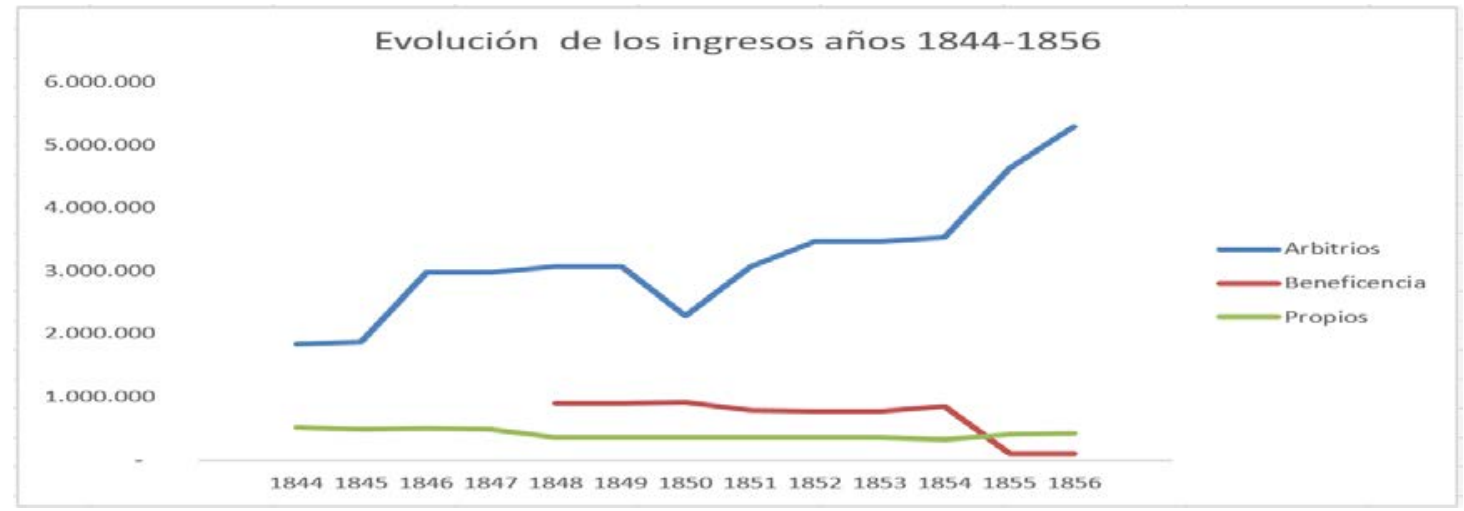

Fuente: elaboración propia a partir de AHMS Presupuestos Sección XX C.A. 1179-1241 años 1833-1857.

El análisis de los ingresos (gráfico 1) confirma el paso de una hacienda patrimonial a una hacienda fiscal donde el peso de la aportación a las arcas públicas recae sobre las clases menos pudientes, debido a la tributación indirecta basada en los consumos.

El peso de la aportación al presupuesto municipal de la contribución territorial e industrial era inferior al de los arbitrios, a pesar de que la ciudad era eminentemente agrícola, debido a la existencia de una alta concentración de la propiedad de la tierra

\footnotetext{
${ }^{61}$ Fuente: INE Escuelas de primera enseñanza existentes en 1855, y sus gastos de personal y material. Anuario 1858.
} 
que, a su vez, ocupaba los lugares de las tomas de las decisiones en la administración municipal.

Los ingresos de productos ordinarios de propios se mantuvieron e incluso descendieron entre 1844 y 1855 . En cambio, los ingresos de los arbitrios pasaron de 1.832.644 reales en 1844 a 5.285.399 reales en 1856. Finalmente, con respecto a los ingresos de la beneficencia se aprecia un descenso bastante acusado entre 1848 y 1856 , sobre todo coincidiendo con la desamortización de Madoz en 1855.

\section{CONCLUSIONES}

Este artículo ha analizado la relación del problema de la escasez de escuelas en el ámbito local, motivada por un déficit presupuestario crónico. Permite establecer un tipo específico de instituciones que benefician y perjudican a determinados sectores de la población en línea con el concepto de élites extractivas creando una senda dependiente en las mismas. En primer lugar, muestra la contradicción entre la legislación que se intenta implantar para modernizar el país, y las prácticas políticas. Muestra los intereses de un grupo social, las élites urbanas, que controlan el Ayuntamiento, y que no coinciden con los intereses generales que están detrás de las nuevas leyes.

En segundo lugar, el texto demuestra la insuficiencia de los recursos destinados a la formación educativa básica. El Ayuntamiento muestra su incapacidad para asumir las nuevas funciones encomendadas.

En un primer periodo, entre 1844 y 1850 , el presupuesto que corresponde a la Instrucción Pública no se dirige a la creación y puesta en funcionamiento de nuevas escuelas, ni a los salarios ni contratación de nuevos maestros, sino que se destina a la rehabilitación de edificios. Esto supone el incumplimiento de la ley pues se establecía un número mínimo de escuelas gratuitas por población. Existió una tendencia, por parte de las autoridades locales, a financiar el establecimiento de centros educativos de enseñanza secundaria, lo que explicaría el abandono de la educación primaria.

En un segundo periodo, entre 1850 y 1854, el presupuesto destinado a Instrucción Pública en la ciudad de Sevilla aumentó debido a una mayor influencia del Estado, a través de la Comisión Superior y el Jefe Político, en tensión permanente con el 
Ayuntamiento. Hay que destacar que esos incrementos se llevaron a cabo sobre los arbitrios de modo que el esfuerzo económico fue evitado por los grandes contribuyentes. Sin embargo, persistió el problema de la financiación, y siguieron destinándose porcentajes importantes del presupuesto a la rehabilitación de edificios. En base a los datos del Censo de 1855 se puede concluir que no se utilizaba la totalidad de los recursos disponibles y que la aportación privada era de las más elevadas del país.

Por último, el proceso de establecimiento de escuelas gratuitas en la ciudad de Sevilla, y las discusiones y decisiones que se sucedieron durante la Década Moderada enlazan con dos debates teóricos relevantes.

Por un lado, el Ayuntamiento, con la influencia de la élite local, se relaciona con las características propias de las instituciones extractivas, que permiten emplear los recursos públicos para obtener un beneficio privado; sería una forma de perpetuar la posición hegemónica de las élites, restringiendo el acceso de las masas a la educación.

Al mismo tiempo, refuerza la idea del profundo efecto negativo sobre el desarrollo económico de un territorio, Sevilla, que había iniciado su declive hacía tiempo y que todavía irá, en términos relativos, más atrás en las siguientes décadas.

Como señala Feito, una auténtica democracia exige una ciudadanía culta y esta tarea es en buena medida responsabilidad de la escuela ${ }^{62}$.

\section{BIBLIOGRAFÍA}

Acemoglu D. y Robinson J. “¿Por qué fracasan los países? Los orígenes del poder, la prosperidad y la pobreza”. Editorial Deusto, Barcelona, 2012.

Aguilar F. "La enseñanza primaria en Sevilla durante el siglo XVIII”. Boletín de la Real Academia Sevillana de Buenas Letras, 1973, vol. 1, pp. 39-83.

Almuedo, J. Ciudad e industria: Sevilla, 1850-1930. Diputación Provincial de Sevilla, 1996.

Beltrán, F., Díez-Minguela A. y Martínez-Galarraga J. "The shadows of cities: Size, location and the spatial distribution of population in Spain". Cambridge Working Paper Economics: 1749. Cambridge: University of Cambridge, 2017.

Beltrán, F., Díez-minguela A. y Martínez-Galarraga J. "Tracing the Evolution of Agglomeration Economies: Spain, 1860-1991". The Journal of Economic History 78 (1), 2018, pp. 81-117.

Bernal A. La lucha por la tierra en la crisis del Antiguo Régimen. Madrid: Ediciones Taurus S.A., 1979.

\footnotetext{
${ }^{62}$ R. Feito. "Escuela y Democracia”. Politica y Sociedad, volumen 47 Núm. 2, 2010, pp. 60.
} 
Collado M. "Proyecto de la Real Sociedad Económica del Amigos del País, de establecimientos de escuelas gratuitas para la ciudad de Sevilla, en el año 1837”. Cuestiones Pedagógicas 2, 1985, pp. 143-150.

Collantes, F. "Las disparidades educativas en la España rural contemporánea, 18602000: un análisis comparado de las comarcas montañosas", Revista de Demografía Histórica. Volumen XXII, II, 2004, segunda época, pp.15-52

Comín F. "La corrupción permanente: el fraude fiscal en España". Revista de Historia Contemporánea Hispania Nova, 2018, número 16, pp. 481-521.

Comín, F. Martín, P. y Vallejo, R. "La Hacienda por sus ministros. La etapa liberal de 1845 a 1899”, Prensas Universitarias de Zaragoza, Zaragoza, 2006, pp. 73.

Cózar R. y García F. "La Enseñanza De Primeras Letras En Las Tierras De Albacete a Finales Del Antiguo Régimen". Tiempos modernos: Revista Electrónica de Historia Moderna, volumen 8, $\mathrm{n}^{\mathrm{o}}$ 31, 2015, pp 68-72.

Espigado G. "Aprender a leer y escribir en el Cádiz del 800. Universidad de Cádiz, Cádiz, 1996.

Feito R. "Escuela y Democracia". Politica y Sociedad, volumen 47 n 2, 2010, pp. 60.

Galor, O. "Inequality and Economic Development". An overview. Working papers from Brown University 3, 2009.

Galor O. y Zeira J. "Income Distribution and Macroeconomics". Review of Economic Studies. Oxford University Press 60 (1), pp. 35-52, 1993.

Galor, O. Moav O. y Vollrath D. "Inequality in Landownership, the Emergence of Human-Capital Promoting Institutions, and the Great Divergence." Review of Economic Studies. Oxford University Press 76 (1), pp. 143-179, 2009.

García, C. "Una lenta y tardía transformación: Las haciendas locales en el tránsito del absolutismo al liberalismo" en Las transformaciones económicas de la revolución liberal en España (1808-1874). Revista Internacional de Ciencias Sociales 37, pp. 93-107, 2018.

Giménez, C. "A short history of social welfare organizations in Seville, from their foundation still 1900". Revista de Historia Contemporánea Hispania Nova 6, 2006.

Go S. y Lindert P. "The Uneven Rise of American Public Schools to 1850". The Journal of Economic History 70 (1), pp. 1-26, 2010.

Gómez J.L. et al. "Los maestros de primeras letras en La Rioja a mediados del siglo XVIII". Cuadernos de investigación histórica, Universidad de La Rioja, 2019, pp. 127.

Juif D. Determinants of Long-Run Human Capital Formation. PHD in Economic History. Tubinga: Universidad de Tubinga, 2014.

Laspalas J. "Primary Schools in Eighteenth-Century Spain: Assessment and Research Perspectives". History of Education \& Children's Literature. Vol.7 n 2, 2012. pp. 11-32.

Levi G. La herencia inmaterial: La historia de un exorcista piamontés del siglo XVII. Edición Nerea, Madrid, 1990.

Martínez A.P. "La protección social en la época liberal: de la beneficencia a la previsión social (1820-1908)". Revista Internacional de Ciencias Sociales, [s. 1.], n. 37, 2018, pp. 110-112.

Mokyr J. The Enlightened Economy: An Economic History of Britain 1700-1850. New Haven: Yale University Press, 2010.

Montero A. La enseñanza primaria pública en Sevilla (1857-1900). Desde la promulgación de la Ley Moyano hasta la creación del Ministerio de Instrucción 
Pública. Universidad de Sevilla, Departamento de Teoría e Historia de la Educación y Pedagogía Social, 1996.

Núñez C. La fuente de la riqueza. Educación y desarrollo económico en la España Contemporánea. Madrid, Alianza Editorial, 1992.

Núñez C. "Los determinantes del atraso educativo" en A. Carreras y X. Tafunell (eds) Estadísticas Históricas de España siglos XIX-XX. Bilbao: Fundación BBVA, 2005.

Núñez C. y Tortella, G. La maldición divina. Ignorancia y atraso económico en perspectiva histórica. Madrid, Alianza Editorial, 1993.

Ojeda R. "Aproximación al estado de la educación a mediados del siglo XIX a través del diccionario de Madoz: El caso de La Rioja”. Berceo, Logroño, 1999, No 136, pp. 139-150.

Tortella G. y Núñez C. El desarrollo de la España contemporánea. Madrid: Alianza Editorial, 2017.

Vallejo R. "Los amillaramientos como fuente estadística: una visión crítica desde la contribución territorial”. Revista Historia Agraria 20, 2000, pp. 115. 